\title{
ENERGIEAKKOORD Y KLIMAATAKKOORD. LOS ACUERDOS COMO INSTRUMENTO DE COORDINACIÓN PARA LAS POLÍTICAS NEERLANDESAS DE CAMBIO CLIMÁTICO
}

\section{ENERGIEAKKOORD AND KLIMAATAKKOORD. THE AGREEMENTS AS A COORDINATION MECHANISM FOR DUTCH CLIMATE CHANGE POLICY}

\author{
LAURA PRESICCE ${ }^{1}$ \\ Investigadora predoctoral \\ Universitat Rovira i Virgili, Departamento de Derecho Público \\ Centre d'Estudis de Dret Ambiental de Tarragona \\ laura.presicce@urv.cat
}

Fecha de recepción: 28 de febrero de 2020 / Fecha de aceptación: 15 de mayo de 2020

RESUMEN: Los Países Bajos tienen una larga tradición en la búsqueda del consenso sobre objetivos y mecanismos para el despliegue de políticas sociales y económicas, a través de consultas y acuerdos entre distintas partes implicadas. Esta modalidad de "gobierno por acuerdos" pone de manifiesto la naturaleza multiforme y descentralizada de las esferas sociopolíticas y del poder en los Países Bajos. Los acuerdos del gobierno nacional con los interlocutores sociales, con otros niveles de gobierno y hasta con otros partidos políticos, sobre elementos de la política gubernamental han contribuido a configurar la gobernanza en los Países Bajos durante siglos. La gobernanza basada en acuerdos representa, en definitiva, un aspecto consolidado de la sociedad

\footnotetext{
1 El presente estudio ha sido realizado con el apoyo del Agaur, de la Secretaria d'Universitats i Recerca del Departament d'Empresa i Coneixement de la Generalitat de Catalunya y del Fondo Social Europeo y se enmarca en el proyecto de investigación "Constitución climática global: gobernanza y derecho en un contexto complejo" (referencia DER2016-80011-P) financiado por el Ministerio de Economía y Competitividad, dentro del Programa Estatal de Fomento de la Investigación Científica y Técnica de Excelencia, Subprograma Estatal de Generación del Conocimiento, en el marco del Plan Estatal de Investigación Científica y Técnica y de Innovación 2013-2016.
} 
pluralista y del Estado unitario pero descentralizado neerlandés. A partir de estas premisas, el propósito del presente trabajo es examinar los acuerdos energético y climático neerlandeses para favorecer la transición energética y la acción climática. Se valorarán, concretamente, en su perspectiva de instrumentos de gobernanza colaborativa y multinivel, como marco para las políticas climáticas.

RESUM: Els Països Baixos tenen una llarga tradició en la cerca del consens sobre objectius i mecanismes per al desplegament de polítiques socials i econòmiques, a través de consultes i acords entre diferents parts implicades. Aquesta modalitat de "govern per acords" posa de manifest la naturalesa multiforme i descentralitzada de les esferes sociopolítiques i del poder als Països Baixos. Els acords del govern central amb els interlocutors socials, amb altres nivells de governs i fins i tot amb els partits polítics de l'oposició, sobre elements de la política governamental han contribuït a configurar la governança als Països Baixos durant segles. La governança basada en acords representa, en definitiva, un aspecte consolidat de la societat pluralista i de l'Estat unitari però descentralitzat neerlandès. A partir d'aquestes premisses, el propòsit del present treball és examinar els acords energètic $i$ climàtic neerlandesos per a afavorir la transició energètica i l'acció climàtica. Es valoraran, concretament, en la seva perspectiva d'instruments de governança col-laborativa i multinivell, com a marc per a les polítiques climàtiques.

ABSTRACT: The Netherlands has a long tradition of seeking consensus on objectives and mechanisms for the deployment of social and economic policy, through consultation and agreement between different stakeholders. This form of 'government by agreement' shows the multiform and decentralised nature of the socio-political and power spheres in the Netherlands. Central government agreements with the social partners, with other levels of government and even with opposition political parties, on elements of government policy have helped to shape governance in the Netherlands for centuries. Agreement-based governance ultimately represents an established aspect of the pluralistic society and the unitary but decentralised Dutch state. Against this backdrop, the purpose of this paper is to study Dutch energy and climate agreements in order to support energy transition and climate action. They will be considered in their perspective 
as instruments of collaborative and multilevel governance, as a framework for climate policies.

PALABRAS CLAVE: Energieakkoord - Klimaatakkoord - Gobernanza multinivel - Acuerdo climático - Participación social.

PARAULES CLAU: Energieakkoord - Klimaatakkoord - Governança Multinivell - Acord climàtic - Participació social.

KEYWORDS: Energieakkoord - Klimaatakkoord - Multilevel governance Climate agreement - Social engagement.

SUMARIO: I. Introducción. II. Los "Akkoords" y el "poldermodel" en la tradición neerlandesa. 1. El "poldermodel" verde. 2. El rol del Consejo Económico y Social (SER). III. El "Energieakkoord". 1. Estructura y objetivos. Un breve análisis. 2. Seguimiento, evaluación e información pública. IV. El "Klimaatakkoord". 1. Estructura y funcionamiento. 2. "Klimaatakkoord", "Klimaatwet" y "Klimaatplan". 3. El "Klimaatakkoord" y el paquete de "medidas Urgenda". V. Consideraciones analíticas. 1. Coordinación entre niveles de gobierno y administraciones. 2. Búsqueda de la aceptación social y de la participación activa de los ciudadanos. 3. Acuerdos como base para la legislación posterior. 4. Fortalecimiento del rol del gobierno respecto al parlamento. 5. Negociación con los grupos de interés. VI. Conclusiones. VII. Bibliografía y webgrafía básica.

\section{INTRODUCCIÓN}

Los Países Bajos, tras la ratificación del Acuerdo de París, se han comprometido a llevar a cabo una política climática ambiciosa a corto, medio y largo plazo, con el objetivo de reducir las emisiones de gases de efecto invernadero del País en un $49 \%$ para 2030 y en un $95 \%$ para 2050, en comparación con los niveles de 1990. Sin embargo, el Gobierno neerlandés ha señalado que, para lograr los citados objetivos, no es suficiente perfilar una política climática ambiciosa, sino que a ello debe añadirse la participación e implicación de todos los niveles de gobierno y de la sociedad civil, ya desde la fase de delineación y diseño de políticas.

Por este motivo, tras un año de negociaciones, el 30 de junio de 2019, el gobierno, las provincias, los municipios, las juntas de aguas ${ }^{2}$, los agentes

\footnotetext{
2 La junta de agua (waterschap) es una administración pública funcional, que se encarga de la gestión del agua en un área determinada. Para sus funciones, se puede consultar la página web del Rijksoverheid, "Taken van een waterschap" <https://www.rijksoverheid.nl/onderwerpen/waterschappen/taken-waterschap> [Última consulta: 24/9/2019].
} 
sociales $^{3}$ y muchas empresas han suscrito un Acuerdo por el clima, conocido como Klimaatakkoord ${ }^{4}$. El citato Acuerdo ha constituido la base para la Klimaatwet, o Ley Climática, y ha trazado la ruta de la acción climática neerlandesa en su conjunto.

El Klimaatakkoord podría representar un interesante modelo para que las políticas climáticas nacionales resulten más consensuadas y compartidas con los niveles de gobierno subnacionales, así como aceptadas por la sociedad civil. De tal suerte que supondría una herramienta eficaz para poder implementar políticas climáticas más eficaces, efectivas y coherentes. Partiendo de estas consideraciones, el propósito del presente estudio es examinar los acuerdos nacionales entre múltiples partes interesadas, herramienta peculiar de la tradición neerlandesa, en su vertiente de instrumento marco para favorecer la transición energética y la acción climática. A tal fin, después de una parte general acerca de los akkoords y del modelo polder, se procederá a un estudio de la arquitectura organizativa del Klimaatakkoord, o Acuerdo Climático, y de su predecesor, el Energieakkoord, o Acuerdo para la Transición Energética, entrando a valorar los aspectos positivos y negativos de ambos instrumentos. Prescindiremos, en cambio, de un análisis pormenorizado del contenido material de los citados acuerdos.

\section{LOS “AKKOORDS" Y EL “POLDERMODEL” EN LA TRADICIÓN NEERLANDESA}

Una política gubernamental sin coordinación entre los niveles de gobierno y sin la participación de la sociedad civil, en opinión del Gobierno nacional neerlandés, ofrece una continuidad insuficiente para la necesaria transición energética ${ }^{5}$ y

\footnotetext{
3 Entenderemos como agentes o actores sociales, en este estudio, las organizaciones empresariales y sindicales, así como las ONG y las plataformas ciudadanas.

${ }^{4}$ El texto del Klimaatakkoord (Anexo del Documento parlamentario 32813, no H) se puede consultar en <https://zoek.officielebekendmakingen.nl/blg-890294>. La versión en inglés del "National Climate Agreement" se puede consultar en: $<$ https://www.klimaatakkoord.nl/binaries/klimaatakkoord/documenten/publicaties/2019/06/28/nat ional-climate-agreement-the-

netherlands/20190628+National+Climate+Agreement+The+Netherlands.pdf> [Última consulta: 21/11/2019].

5 SER, Energieakkoord 2018 en 5 jaar borging, 2018, p. 3. Disponible en: <https://publicaties.energieakkoordser.nl/2018/cover> [Última consulta: 21/9/2019].
} 
para hacer frente a la crisis climática. Políticas de cambio climático consensuadas y aceptadas socialmente son, en palabras del Gobierno, imprescindibles para alcanzar los compromisos climáticos de los Países Bajos ${ }^{6}$ en el escenario europeo y mundial.

Los Países Bajos tienen una larga tradición en la búsqueda del consenso sobre objetivos y mecanismos para el despliegue de políticas sociales y económicas, a través de consultas entre las distintas partes. La modalidad de "gobierno por acuerdos" denota la naturaleza multiforme y descentralizada del escenario político y social y del poder en los Paises Bajos ${ }^{7}$.

Los acuerdos del Gobierno nacional con los interlocutores sociales, con otros niveles de gobierno y hasta con otros partidos políticos, sobre elementos de la política gubernamental, representan un aspecto consolidado que ha contribuido a configurar la gobernanza en los Países Bajos durante siglos ${ }^{8}$. Este background ha hecho posible que la actual política climática y energética interna neerlandesa se asiente en acuerdos políticos, entre el Gobierno central, las provincias, los municipios, las juntas de agua, las empresas y los agentes sociales.

$\mathrm{KOOLE}^{9}$ destaca, entre la experiencia neerlandesa de ámbito nacional, diferentes categorías de acuerdos con características muy heterogéneas entre ellos: los acuerdos político-sociales, que involucran a representantes políticos y grupos de interés; los acuerdos parlamentarios que se celebran entre grupos

\footnotetext{
${ }^{6}$ Ibid. Traducción propia.

${ }^{7}$ Así se destaca en el Informe anual del Consejo de Estado neerlandés de 2013. Raad Van State, Jaarverslag van de Raad van State over 2013, 2014. Disponible en $<$ https://jaarverslag.raadvanstate.nl/2013/downloads/jaarverslag-raadvanstate-2013.pdf>. [Última consulta: 20/05/2020].

8 En pasado, esta coordinación se realizaba en los consejos consultivos, en los que estaban representadas los distintos actores sociales y los relativos intereses; ahora, el Acuerdo parece ser un sustituto de estos. Vid. "Regeren bij akkoord onderstreept het pluriforme en gedecentraliseerde karakter van het politieke en maatschappelijke krachtenveld. Akkoorden met sociale partners, mede-overheden en politieke tegenstanders over elementen van het regeringsbeleid zijn niet nieuw. Het is een aspect van een pluriforme samenleving en een gedecentraliseerde eenheidsstaat die het besturen in Nederland al eeuwen bepaalt. Vroeger vond de nodige afstemming plaats in adviesraden waarin maatschappelijke verbanden en belangen vertegenwoordigd waren; het akkoord blijkt daar nu de vervanging van". Raad Van State, Jaarverslag van de Raad van State over 2013, cit.

${ }_{9}^{9}$ Ruud A. Koole, "Is een 'akkoorden-democratie' wel een democratie?", RegelMaat, 34.2 (2019), pp. 95-96. Disponible en: <https://www.bjutijdschriften.nl/tijdschrift/regelmaat/2019/2/RM_0920055X_2019_034_002_002.pdf> [Última consulta: 20/5/2020].
} 
parlamentarios (Kamerfracties); y los acuerdos entre distintas administraciones territoriales ${ }^{10}$.

Los acuerdos objeto de estudio pueden incluirse prima facie en la primera categoría de acuerdos políticos-sociales, aunque en realidad son acuerdos de naturaleza híbrida. El Klimaatakkoord, por ejemplo, es un acuerdo complejo que comprende también elementos de las otras dos categorías. El rumbo asumido por los Paises Bajos se puede alinear con los patrones del modelo teórico de collaborative governance, no solamente por lo que respecta la implementación, sino también en el diseño de las políticas ambientales y climáticas ${ }^{11}$.

Este paradigma de "democracia de negociación" se enmarca en el muy peculiar sistema de la tradición neerlandesa de los polders o poldermodel. El modelo de polder no configura simplemente un mecanismo de consulta puntual entre diferentes partes; se trata, más bien, de un sólido mecanismo de cooperación entre los interlocutores institucionales y sociales, surgido en ámbito de negociación laboral ${ }^{12}$, y que ha tenido un gran éxito en el pasado. En este modelo los intereses públicos y privados, no siempre alineados entre sí, intentan enlazarse y equilibrarse, para conseguir objetivos de interés común. Así, en palabras de SCHREUDER, en el ámbito laboral, "[t]he polder model expresses cooperation between capital, labor, and the state"13.

El éxito de las negociaciones del procedimiento polder en la política socioeconómica neerlandesa representó un modelo para los primeros intentos de introducir técnicas de negociación institucionalizada en los campos de la sostenibilidad medioambiental y de la energía.

\section{El "poldermodel" verde}

En cuanto a la evolución de la política ambiental neerlandesa, ScHREUDER diferencia tres fases: la primera fase (1970-1983) estaba enfocada en un régimen de tipo "command and control regulation", una regulación que podríamos definir

\footnotetext{
10 Un ejemplo de los acuerdos entre diferentes administraciones (Bestuursakkoord) es el programa IBP, al que se hará referencia a lo largo del presente estudio.

11 Matthew C. Nowlin, Environmental Policymaking in an Era of Climate Change (Routledge, 2019).

12 Kees Vos, Paul de Beer, Lieve De Lathouwer, " Verleden en toekomst van het poldermodel", Tijdschrift voor Arbeidsvraagstukken, 18.4 (2002), pp. 403-10.

${ }^{13}$ Yda Schreuder, "The Polder Model in Dutch Economic and Environmental Planning", Bulletin of Science, Technology \& Society, 21.4 (2001), pp. 237-45.
} 
de arriba hacia abajo. En la segunda fase (1984-1989) se empezaron a tomar en consideración a las partes interesadas en el diseño de políticas y en la implementación legislativa; asimismo se emprendieron los primeros pasos para la cooperación entre el Gobierno, las empresas y los grupos de interés ambientales. Finalmente, en la tercera fase (1990-1999) el modelo del command and control fue remplazado por el modelo de acuerdos y negociaciones ${ }^{14}$. A tal propósito, según algunos autore ${ }^{15}$, los planes de expansión del aeropuerto de Ámsterdam ${ }^{16} \mathrm{y}$ del puerto de Rotterdam pueden ser considerados indirectamente como los precursores subyacentes de los logros conseguidos en el Energieakkoord y Klimaatakkoord.

Por otro lado, según SCHREUDER, las primeras semillas del poldermodel verde "groen poldermode ${ }^{117}$ son incluso anteriores a los citados planes, pudiendo hallarse en los Planes Nacionales de Política Ambiental neerlandés ${ }^{18}$. Algunas partes interesadas (en concreto, grupos ambientalistas, organizaciones no gubernamentales en general, sindicatos y ayuntamientos) reclamaron que no fueron suficientemente consultadas durante las negociaciones del primer Plan (NMP1) de 1989, de manera que en el segundo Plan (NMP2) de 1993 se reconoció un papel más relevante a los gobiernos locales ${ }^{19} \mathrm{y}$, posteriormente, en el tercero (NMP3), de 1998, y, sobre todo, en el cuarto (NMP4), de 2001, se amplió notablemente la participación a la sociedad civil ${ }^{20}$.

El recorrido desde el poldermodel al groen poldermodel, sin embargo, no ha sido sencillo ni lineal, debido a las importantes diferencias entre la política ambiental

\footnotetext{
14 Vid. Schreuder, cit., p. 239.

15 Entre todos, véase Elisabeth Musch, "The Energy Agreement (Energieakkoord) of the Netherlands in the European context", ECPR General Conference, 2018, pp. 1-22 <https://ecpr.eu/Filestore/PaperProposal/d02f08ae-15f3-4bd3-8264-29229b001cfb.pdf> [Última consulta: 20/5/2020].

${ }^{16}$ El caso de la ampliación del aeropuerto de Ámsterdam podría ser considerado, sin embargo, un intento fallido. Vid. Pieter Glasbergen, "The green polder model: Institutionalizing multistakeholder processes in strategic environmental decision-making", European Environment, 12.6 (2002), pp. 309. Asimismo, véase Jeroen Touwen, Coordination in Transition: The Netherlands and the World Economy, 1950-2010 (Brill, 2014), pp. 186 ss.

$17 \mathrm{El}$ término "groen polder" fue propuesto por Paul Rosenmöller, presidente del partido parlamentario GroenLinks en la Cámara Baja en 1997. La expresión es utilizada, entre otros, por Musch (cit., p. 11) y Glasbergen (cit., pp. 305-315).

${ }^{18}$ Nationaal Milieubeleidsplan. Vid. Schreuder, cit., p. 239.

${ }^{19}$ Schreuder, cit., pp. 239-240.

${ }^{20}$ Vid. Thomas Hoppe et al., "Transition management and the sustainable nutrients economy in the Netherlands", Tutkimusraportti Research Report 25, 2012, pp. 1-37. En el mismo sentido, Adrian Smith y Florian Kern, "The transitions storyline in Dutch environmental policy", Environmental Politics, 18.1 (2011), pp. 78-98.
} 
y política la socioeconómica de ámbito de negociación laboral. Como pone de manifiesto GLASBERGEN ${ }^{21}$, los problemas son diferentes y lo son también los actores involucrados. De acuerdo con el citado autor, en la política socioeconómica laboral, el campo de juego es bastante claro: los temas son esencialmente de interés nacional e involucran, además del Gobierno nacional, también a organizaciones patronales y sindicatos, cuyos intereses están esencialmente marcados por la divergencia entre el interés por el trabajo y el interés por el capital. En el ámbito de la política medioambiental, el escenario resulta mucho más complejo y variado. Si cabe, pues se hallan involucradas organizaciones sociales grandes y pequeñas, muchos - y diferentes - intereses sectoriales, así como los gobiernos subestatales, en forma de autoridades municipales, provinciales y las juntas de agua. Estos gobiernos, que apenas participan en la política socioeconómica laboral, en cambio, representan una amplia gama de intereses divergentes en ámbito medioambiental ${ }^{22}$.

Ésta es la razón por la cual, refiriéndose al Energieakkoord y al Klimaatakkoord, KOOLE se refiere al "Polder $2.0^{23}$ puesto que, respecto a los acuerdos precedentemente estipulados, los acuerdos objeto de análisis aumentan su amplitud y aspiran a aumentar su consenso, comprendiendo no solamente representantes del gobierno y grupos de interés, sino también, como ya se ha indicado, administraciones subestatales, organizaciones no gubernamentales, asociaciones medioambientales y de representación ciudadana.

Los mencionados acuerdos, desde un punto de vista formal, se presentan como documentos exhaustivos que incluyen detalladas hojas de ruta, redactados y pactados después de intensas reuniones entre los distintos actores mencionados. Desde un punto de vista sustancial, configuran un importante instrumento político de collaborative y multilevel governance, en la medida en que abarcan a diferentes niveles de administración y cuentan también, como se ha comentado anteriormente, con la presencia de actores de la sociedad civil. Aunque se trate de acuerdos políticos que, por ende, no tienen fuerza legal propia, estimamos que su alcance no puede y no debe subestimarse, ya que

\footnotetext{
${ }^{21}$ Glasbergen, cit., p. 308.

22 Glasbergen, cit., p. 308.

${ }^{23}$ Koole, cit., p. 100.
} 
gozan de una legitimidad política que los legitimados para formular las políticas climáticas no pueden ignorar. Y, con ello, constituyen la base para el desarrollo normativo posterior.

\section{El rol del Consejo Económico y Social (SER)}

Un papel fundamental en los acuerdos tiene que ser reconocido al Consejo Económico y Social de los Países Bajos ${ }^{24}$ (SER), un consejo asesor independiente ${ }^{25}$, instituido en 1950 para asesorar al gobierno en materia de política socioeconómica. Este organismo de carácter consultivo, que ejerce una notable influencia en la determinación de las políticas del Gobierno, consta de 33 miembros entre organizaciones patronales, sindicados de trabajadores y miembros independientes (normalmente profesores universitarios) designados por el rey. Si bien el SER se ocupa de temas medioambientales y energéticos desde los años setenta, sólo recientemente han entrado a formar parte de sus grupos de trabajo asociaciones ambientalistas, además de asociaciones de consumidores y representantes de otros niveles de administración.

EI SER es el organismo encargado de vehicular la participación de los interlocutores sociales en el diseño de la política socioeconómica neerlandesa, a través, entre otros mecanismos ${ }^{26}$, de recomendaciones y de acuerdos. Asimismo, tiende a convertirse en un organismo de mediación y coordinación, con el fin de proteger y velar para que, sobre todo en las mesas de negociación, unos intereses sectoriales no prevalezcan sobre otros. En cuanto al Energieakkoord, por ejemplo, el SER ha actuado como facilitador del mismo y su función ha sido concretamente buscar un equilibrio entre las dimensiones económica, ecológica y social en el seno de una noción amplia de "bienestar" latu sensu27. Una vez formalizados los acuerdos, la labor del SER es

\footnotetext{
24 Sociaal-Economische Raad.

${ }^{25}$ Aunque haya sido instituido por Ley [Wet op de Sociaal-Economische Raad], el SER no es una institución gubernamental, siendo tanto sustancial como financieramente independiente. Concretamente, el SER es financiado a través del Fondo General de Desempleo.

${ }^{26}$ Para conocer, en detalle, todas las funciones del SER, consúltese su página web "What does the SER do?": <https://www.ser.nl/en/SER/About-the-SER/What-does-the-SER-do> [Última consulta: 24/07/2019].

${ }^{27}$ Elisabeth Musch, cit., p. 6.
} 
principalmente el seguimiento y la publicidad de los avances de los acuerdos; tarea ex post, en la que se profundizará más adelante.

Es importante destacar que, aunque los gobiernos no están obligados a tener en cuenta las recomendaciones del SER, en la práctica "cuanto mayor sea el acuerdo entre los interlocutores sociales [...] y los miembros de la corona, cada vez es más difícil para un gabinete ignorar una recomendación del SER"28, así que su peso resulta ser significativo. Sin embargo, se han vertido algunas dudas sobre la independencia del SER respecto del Gobierno, en las negociaciones, al considerar que, por un lado, es el mismo Gobierno que impulsa los acuerdos y utiliza el SER como mediador y negociador; y, por el otro, que la negociación tiene por objeto establecer la ruta a seguir y no los objetivos, fijados de forma unilateral por el Gobierno mismo.

\section{EL "ENERGIEAKKOORD"}

Centrándonos ahora en el tema objeto de estudio, seguiremos con el análisis de los dos acuerdos medioambientales pactados por el Gobierno nacional con los gobiernos subestatales, las empresas y los agentes sociales: el Energieakkoord de septiembre de 2013 y el Klimaatakkoord, firmado en junio de 2019. En cuanto al primero, podemos considerarlo el precursor del Klimaatakkoord y, por este motivo, estimamos que su análisis es de fundamental importancia para entender el segundo. Además, debido a que han transcurrido ya siete años desde su aprobación, se podrá valorar también su implementación. Cabe traer a colación, finalmente, que, tras la aprobación del Klimaatakkoord, se han establecido mecanismos para que el Energieakkoord confluya y se integre en el primero ${ }^{29}$.

\footnotetext{
28 Traducción propia. Vid. el apartado tercero "Invloed en prestaties" en la página web Parlement.com, <https://www.parlement.com/id/vh8Inhrq7yaq/sociaal_economische_raad_ser> [Última consulta: 24/09/2019].

${ }_{29}$ Véase el Documento Parlamentario 32813 N. 443, de 20 de diciembre de 2019 y su anexo 918359. Consultable en <https://zoek.officielebekendmakingen.nl/kst-32813-443.html> [Última consulta: 20/01/2020].
} 


\section{Estructura y objetivos. Un breve análisis}

En línea con los objetivos europeos 20-20-2030, el Gobierno neerlandés negoció, bajo impulso del SER, un Acuerdo para la transición energética, el Energieakkoord ${ }^{\beta 1}$ que, después de ocho meses de negociaciones, fue finalmente adoptado en septiembre de 2013 por más de 47 instituciones y actores sociales. Los cuatro objetivos generales del Acuerdo preveían concretamente: un ahorro promedio de eficiencia energética de 1,5\% por año (sumando una reducción de 100 Petajoules - en adelante PJ - para 2020); un aumento de la proporción de energía generada a partir de fuentes renovables del 4,4\% en 2013 y del $14 \%$ en 2020, de conformidad con los acuerdos de la Unión Europea; un aumento adicional de esa proporción al 16\% en 2023; y la creación, al menos, de 15000 empleos adicionales para $2020^{32}$.

El Acuerdo fue el fruto de numerosas reuniones, en mesas de negociación, entre representantes del Gobierno nacional y de los gobiernos locales, asociaciones de empresarios y sindicatos, organizaciones ambientales, instituciones financieras, ONG y otros stakeholders ${ }^{33}$. Para alcanzar este Acuerdo se organizaron también un gran número de reuniones con organizaciones de la

\footnotetext{
${ }^{30}$ El paquete de medidas de la UE sobre clima y energía hasta 2020 establecía como objetivos: $20 \%$ de reducción de las emisiones de gases de efecto invernadero (en relación con los niveles de 1990), $20 \%$ de energías renovables en la UE; $20 \%$ de mejora de la eficiencia energética. Véase la página web "Paquete de medidas sobre clima y energía hasta 2020", <https://ec.europa.eu/clima/policies/strategies/2020_es> [Última consulta: 24/07/2019].

31 "The Ministry of Economic Affairs had initiated the negotiations in response to an advice of the SER produced on behalf of the Ministry. The delegation to the SER to conduct negotiations meant an involvement of one of the most important advisory councils in the Dutch political system". Musch, cit., p. 2.

${ }^{32}$ Respecto a las correlaciones entre el conocido Caso Urgenda y el Acuerdo energético, cabe aquí destacar que la reducción de emisiones de gases de efecto invernadero no aparece en los objetivos del Acuerdo, por lo cual el Energieakkoord no puede ser considerado, en nuestra opinión, una respuesta al juicio que, en aquel entonces (2013) acababa de empezar. De hecho, la única referencia al Energieakkoord contenida en la citación se refiere justamente a la falta de previsión de reducción de emisión de GEI en el Acuerdo, además de su falta de vinculatoriedad. "In September 2013, an Energy Agreement made by a number of representative organisations was embraced by the State. Besides the fact that this agreement is in no way legally binding on its parties, it does not provide for any emissions reductions and therefore has no relevance to these proceedings". Vid. Summons in the Case: Urgenda Foundation v. Kingdom of the Netherlands (version of 25 June 2014), 2.3 (74). Disponible en: <https://www.urgenda.nl/wpcontent/uploads/Translation-Summons-in-case-Urgenda-v-Dutch-State-v.25.06.10.pdf> [Última consulta: 05/01/2020].

${ }^{33}$ Comunicado de prensa de SER "Broad support for Energy Agreement for Sustainable Growth", 6 de septiembre de 2013. Disponible en: <https://www.energieakkoordser.nl/nieuws/broadsupport-energy-agreement.aspx> [Última consulta: 18/07/2019].
} 
sociedad civil y se llevaron a cabo numerosas reuniones entre la ciudadanía en general ${ }^{34}$.

En cuanto a las administraciones territoriales, el Gobierno central involucró en las negociaciones a las provincias, los municipios y las autoridades del agua, a través de sus organizaciones representativas: la Asociación de las Provincias de Países Bajos - IPO (Interprovinciaal Overleg) -, la Asociación de Municipios Holandeses - VNG (Vereniging van Nederlandse Gemeenten) - y la Asociación de Autoridades Holandesas del Agua - (Unie van Waterschappen) -, las cuáles asumieron un papel representativo y de coordinación interna muy activo.

Los focos de los grupos de trabajo se concentraron en intensas discusiones sobre los cuatro ámbitos principales del Acuerdo: el ahorro de energía, la energía renovable, la innovación y el sector del transporte. Además, un grupo directivo encabezado por el presidente del SER supervisó los trabajos en su totalidad. Los resultados de las mesas de negociación se desglosaron en doce pilares ${ }^{35}$, cada uno de los cuales preveía acciones específicas que cada categoría de actores tenía que llevar a cabo, tal como habían pactado. Las partes, a través del Acuerdo, se comprometían a lograr los objetivos pactados, a elaborar subacuerdos en cooperación con las otras partes y a realizar los ajustes necesarios cuando el progreso resultaba ser insuficiente.

En la siguiente figura, se puede apreciar, ad exemplum, la estructuración y el funcionamiento de un pilar; en concreto se observa el pilar de la generación descentralizada de energía que se divide en diferentes clústers, cada uno de los cuales comprende un amplio abanico de acciones a desarrollar por los diferentes actores.

\footnotetext{
34 "The government also strives for citizen participation as part of the negotiations of the Climate Change agreement. Five regional meetings were organized for interest groups that are not actively involved in the negotiation process. In addition, government actors organized several smaller group talks with citizens". Véase Musch, cit., p. 16.

${ }^{35}$ Ahorro energético en el entorno construido; Ahorro de energía en la industria y la agricultura; Fomento de la producción de energía renovable; Generación descentralizada de energía renovable; Redes de transporte de energía centralizadas; Sistema Europeo de Comercio de Emisiones; Centrales eléctricas de carbón y captura y el almacenamiento de carbono (CCS); Sector del transporte; Empleo y formación; Comercialización de nuevas tecnologías para el crecimiento económico y la exportación; Inversiones de financiación; Redes de Calor sostenible.
} 


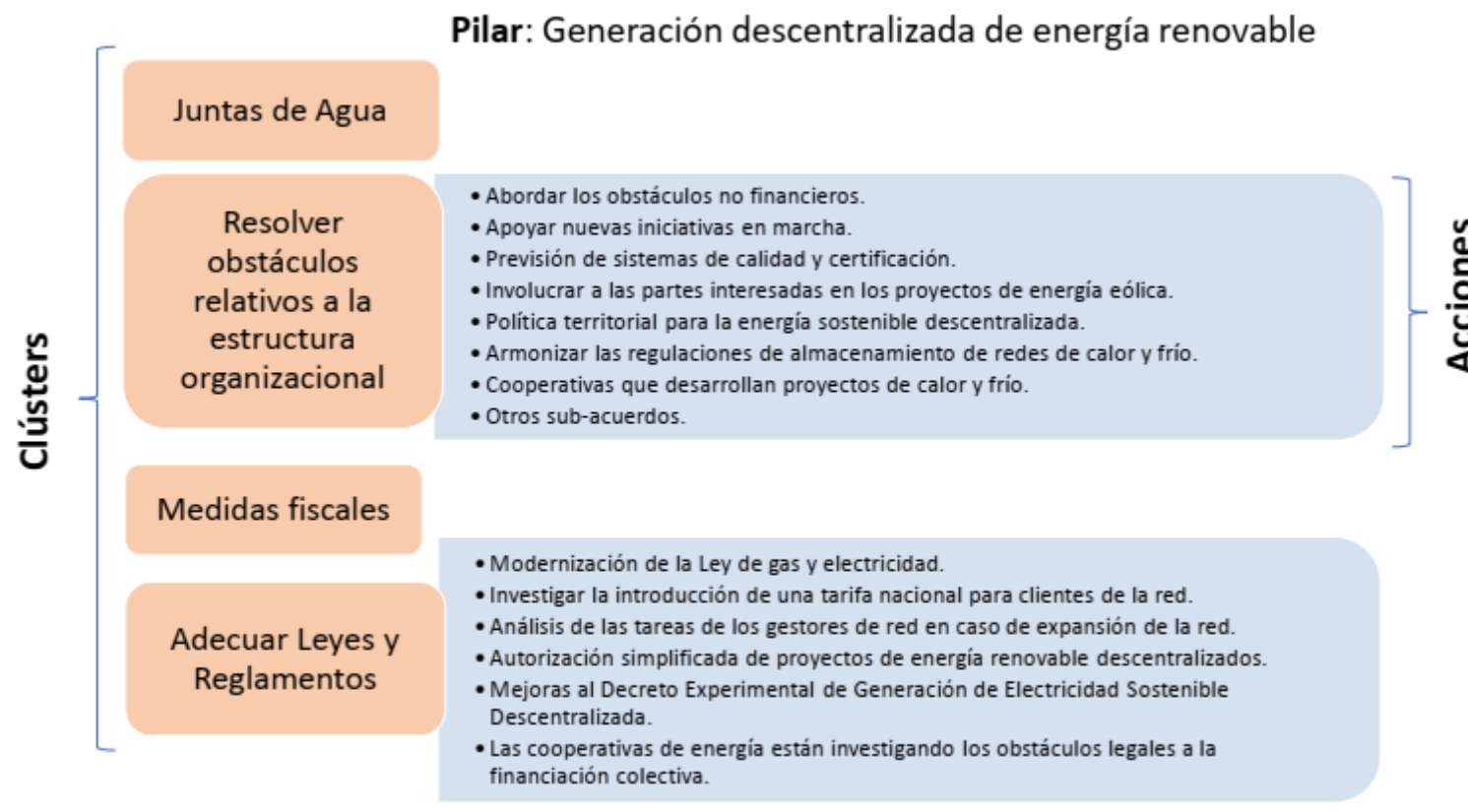

Ejemplo de estructura de un pilar del Energieakkoord, con división en clústers y acciones. Elaboración propia.

\section{Seguimiento, evaluación e información pública}

Una vez suscrito el Acuerdo, el proceso de supervisión ha resultado muy sofisticado y ha abarcado fundamentalmente dos vertientes:

1) la instauración del Commissie Borging Energieakkoord (BEA), un Comité Permanente de Garantía ${ }^{36}$, en el seno del SER, con funciones de supervisión, revisión y aplicación del Acuerdo;

2) una considerable publicidad activa acerca de los logros y resultados del acuerdo.

El BEA congregaba todas las partes del Acuerdo, a través de sus representantes, que se reunían cuatro veces al año, con el objetivo de actualizar el Acuerdo, intercambiar experiencias, examinar los avances e intentar solucionar eventuales obstáculos ${ }^{37}$. Además de la labor del comité permanente, el Acuerdo contaba con una importante estructura de implementación por fases, de forma compuesta y piramidal. Cada acción se hallaba bajo la supervisión de un representante de una de las partes del Acuerdo, que tenía la iniciativa en un tema

\footnotetext{
36 Vid. la página web del SER "Wat doet de Borgingscommissie?", $<$ https://www.energieakkoordser.nl/doen.aspx> [Última consulta: 18/07/2019].

${ }^{37}$ SER, The Agreement on Energy for Sustainable Growth, 2013, cit., p. 6.
} 
específico considerado. El "representante" era el responsable de hacer el seguimiento de la implementación de una acción concreta, en coordinación con los representantes de otras partes interesadas. Además, por cada pilar se establecían uno o dos coordinadores, representantes de las partes que firmaron el Acuerdo. El rol del coordinador del pilar era supervisar el progreso de las acciones que formaban parte del pilar e intercambiar opiniones y estrategias con las partes que se ocupaban de implementarlas. Los coordinadores de los pilares eran los encargados de solucionar los problemas internos; sin embargo, podían solicitar al presidente del Comité que se hiciera cargo de los problemas que resultaban de difícil resolución. A su vez, el Comité, como ya se ha comentado, tenía un rol de información y coordinación más extenso y general, dirigido a todos los pilares. Con la convergencia del Energieakkoord en el Klimaatakkoord, el citado Comité ha cesado sus funciones a partir del 1 de enero de 2020 y ha dejado paso a una estructura de seguimiento que supervisa el proceso de convergencia.

Además del Comité, existía otra importante estructura, la High level overleg, o "Consulta" de Alto Nivel, que consistía en una delegación de las partes firmantes (es decir, no todas las 47 partes estaban representadas), en la que se adoptaban las decisiones políticas más destacadas. El Report del KWINK Groep ${ }^{38}$ considera lógica la creación de esta estructura para poder tomar decisiones de manera eficiente, en vista de la gran cantidad de partes participantes y de las fuertes diferencias existentes entre ellas. Sin embargo, en el mismo estudio se reseñan, por un lado, la necesidad de que la Consulta de Alto Nivel sea más transparente en la toma de sus decisiones ${ }^{39} \mathrm{y}$, por el otro, los riesgos que pueden derivarse del hecho de que partes importantes signatarias del Acuerdo no formen parte de la High level overleg, por ejemplo, los gobiernos municipales.

La segunda vertiente, a la que se da mucho peso, es la transparencia y la publicidad activa. EI SER ha habilitado una plataforma on-line especifica ${ }^{40}$ acerca

\footnotetext{
38 KWINK Groep, Evaluatie Energieakkoord voor duurzame groei. Onderzoek naar de werking van de aanpak van het Energieakkoord voor duurzame groei. (The Hague, 2016), p. 13.

$39 \mathrm{lbidem}$. "De besluitvorming in het High level overleg is voor partijen die hier niet aan deelnemen niet altijd transparant. In de Borgingscommissievergaderingen wordt medegedeeld welke besluiten zijn genomen. Echter, hoe deze tot stand zijn gekomen (welke afwegingen zijn gemaakt) is niet altijd duidelijk voor de overige partijen".

$40<$ https://energieakkoord.ser.nl/> [Última consulta: 20/07/2019].
} 
del Acuerdo de Energía, en la que se desglosan los acuerdos en medidas concretas. En la citada plataforma, cualquier usuario puede encontrar información exacta acerca de cómo se está implementando prácticamente cada pilar. Merece la pena destacar el gran nivel de detalle de la información contenida en la citada página web y la loable labor del SER en la fase de información y de divulgación de los resultados obtenidos en el marco del Energieakkoord. Como se ha podido apreciar en el gráfico anteriormente propuesto, la estructura de la información puesta a disposición del público es tal que cada pilar se encuentra desgranado en varios clústeres $\mathrm{y}$, de cada uno, se detallan los compromisos concretos, el estado de cumplimiento y los resultados obtenidos en cada sector.

Cada año, además, en la citada plataforma se publican dos documentos muy relevantes: el "Informe de progreso" y la "Agenda de Implementación del Acuerdo" para el año siguiente. A estos documentos se suma el "Informe Anual (Nationale Energieverkenningen - NEV) de la Agencia de Evaluación Ambiental de los Países Bajos (Planbureau voor de Leefomgeving - PBL), que proporciona datos sobre la consecución de los objetivos previstos ${ }^{41}$. En el Informe de $2018^{42}$ apreciamos un balance de los primeros cinco años de vigencia del Acuerdo. Se evidencia, en concreto, una disparidad entre los pilares y las partes del Acuerdo que lograron tener un buen funcionamiento y éxito y otros que, al revés, ralentizaron el cumplimiento del Acuerdo debido a diferentes factores, entre los cuales pueden mencionarse las políticas sectoriales en sentido no conforme al acuerdo, llevadas a cabo por el Gobierno nacional o por la Unión Europea; así como la falta de legislación que impulse las acciones derivadas del Acuerdo; la dificultad de la gobernanza coordinada; y la remodelación de las acciones a adoptar (por ejemplo, en el ámbito del cierre de las centrales eléctricas a carbón $\left.{ }^{43}\right)$.

\footnotetext{
41 Energieonderzoek Centrum Nederland, National Energy Outlook 2017: Summary, 2017. Disponible en: <https://www.pbl.nl/sites/default/files/cms/publicaties/pbl-2017-national-energyoutlook-2017_3164.pdf> [Última consulta: 20/07/2019].

42 SER, Energieakkoord 2018 en 5 jaar borging, cit. [Última consulta: 23/07/2019].

${ }^{43} \mathrm{~A}$ tal propósito, véase Musch, cit., pp. 12-13. Para un estudio detallado, véase Raad Van State, Klimaatbeleid in wetgeving en akkoorden. Verslag van de Expertbijeenkomst van de Raad van State op 20 maart 2018, 2018, pp. 22-25. Consultable en:

<https://www.raadvanstate.nl/publish/library/13/klimaatbeleid-in-wetgeving-en-akkoorden.pdf> [Última consulta: 20/07/2019].
} 
Sin embargo, a pesar de los problemas analizados, en los cincos años de vigencia del Acuerdo tres de los cinco objetivos principales del Acuerdo de Energía han sido logrados: se trata del ahorro del consumo final de energía en un promedio de 1,5 por ciento por año; del 16 por ciento de generación de energía renovable en 2023; de al menos 15.000 empleos, en promedio, a tiempo completo por año. Respecto a los otros dos (14 por ciento de generación de energía sostenible en 2020 y 100 PJ de ahorro de energía adicional) ni han sido logrados ni, con las actuales políticas, parece posible que se puedan alcanzar.

Como consecuencia de estas evaluaciones, y para intentar alcanzar el objetivo del ahorro de energía, por una parte, las industrias energéticamente intensivas recientemente acordaron medidas de ahorro específicas para cumplir con sus obligaciones de ahorro de energía y, por otra, el Gobierno ha establecido obligaciones más estrictas para exigir a las citadas industrias. Para citar un ejemplo, el Decreto de Actividades de Gestión Medioambiental (Activiteitenbesluit milieubeheer) $^{44}$ introdujo en 2015, para las empresas que consumían más de 50,000 kWh de electricidad o 25,000 $\mathrm{m}^{3}$ de gas natural, por año, una obligación de tomar medidas de eficiencia energética con un período de amortización de cinco años ${ }^{45}$. A partir del 1 de julio de 2019, con el objetivo de acelerar la eficiencia energética en las citadas empresas, se añade la obligación de que notifiquen, a través del portal "elockef", las medidas de eficiencia energética que han adoptado en cada una de las instalaciones de la empresa. Los municipios son las autoridades competentes para el seguimiento y cumplimiento de la obligación de eficiencia energética; pero si se trata de

\footnotetext{
44 Decreto de 19 de octubre de 2007, por el que se establecen las normas generales para las actividades (Decreto sobre normas generales para las actividades de gestión medioambiental). Este Decreto Ley parece interesante en cuanto, en primer lugar, no considera como medida de eficiencia energética el incremento del uso de energía renovable en la empresa y, además, incluye un listado de medidas concretas de eficiencia energética entre las cuales las empresas pueden elegir. Es más, si en lugar de las medidas reconocidas como obligatorias, se han tomado medidas alternativas, se deberá explicar por qué estas medidas alternativas tienen al menos un potencial de ahorro de energía equivalente.

${ }^{45} \mathrm{~V}$. van 't Lam y E.C. van der Maden, "De informatieplicht en de verplichting tot het treffen van energiebesparende maatregelen uit het Activiteitenbesluit onder de loep", Bedrijfsjuridische berichten, n. 37, Junio (2018), pp. 135-37. Véanse también la página web del Netherlands Enterprise Agency, "Energy efficiency obligation" <https://english.rvo.nl/topics/sustainableenterprise/energy-efficiency-obligation> y la página web "Obligation to report energy-saving measures" <https://business.gov.nl/regulation/obligation-to-report-energy-saving-measures/> [Última consulta: 20/07/2019].
} 
instalaciones grandes $y / 0$ complejas, la competencia pasa a la provincia ${ }^{46}$. La citada medida puede ser considerada un excelente ejemplo del funcionamiento del Acuerdo y de cómo, tras el mismo, la legislación resulta ser el mecanismo fundamental utilizado para concretar y ajustar el camino a seguir para alcanzar los objetivos pactados entre todos los interlocutores.

Podríamos considerar, para concluir, el Energieakkoord como un interesante upgrade del poldermodel, así que, mejorando la definición dada por $\mathrm{KOOLE}^{47}$, en el caso del Energieakkoord podríamos hablar de "Green Polder model 2.0". El paradigma participativo del polder se ha perfeccionado en el Energieakkoord a través de hacer partícipes del Acuerdo a las provincias, municipios, autoridades del agua, empresas y diferentes actores sociales; así como a través de la introducción de nuevos mecanismos de gobernanza participativa y colaborativa. En cuanto a la fase de monitorización, destaca la transparencia y la información activa en la fase de implementación, así como los mecanismos pormenorizados y los instrumentos formales de supervisión piramidal, que han contribuido sin duda a la mejora de la estructura del modelo polder.

\section{EL “KLIMAATAKKOORD”}

El proceso de negociación y de elaboración del Klimaatakkoord, o Acuerdo por el Clima, empezó el 23 de febrero de 2018 (impulsado por el Gobierno, con la ayuda y coordinación del SER) y se prolongó durante más de un año ${ }^{48}$, en el que, por lo menos en dos ocasiones, la opinión pública consideró que no se lograría el acuerdo. Sin embargo, el 30 de junio de 2019, el Gobierno nacional, las provincias, los municipios, las juntas de aguas y numerosas empresas y

\footnotetext{
${ }^{46}$ Las autoridades competentes recuperan el informe en el portal y utilizan la información para verificar si se ha cumplido con la obligación de eficiencia energética y con la obligación de notificación. Asimismo, las autoridades competentes pueden realizar inspecciones, tomar medidas de ejecución o sancionar por incumplimiento. Véase "Dutch Environmental Management Act. Notification of implemented recognized measures", 19 de feberero de 2019, en EcoMatters (web) <https://www.ecomatters.nl/news/changes-in-the-dutch-environmental-management-act/> [Última consulta: 20/07/2019].

47 Vid. supra, nota 23.

48 Acerca de la cronología del Klimaatakkoord, véase el Documento Parlamentario 32813, № H. Disponible en: <https://zoek.officielebekendmakingen.nl/kst-32813-H.html>. Véase, además, Corien Lambregtse, "Overleg tussen politiek en polder: Reconstructie Klimaatakkoord", 12 de septiembre de 2019, SER (web) <https://www.ser.nl/nl/Publicaties/reconstructie-klimaatakkoord> [Última consulta: 18/10/2019].
} 
agentes sociales han subscrito el Klimaatakkoord. Este Acuerdo ${ }^{49}$ constituye una pieza clave de la política climática neerlandesa y, concretamente, es un acuerdo político entre el Gobierno central, los gobiernos territoriales, numerosas organizaciones y empresas de los Países Bajos, con el objetivo de establecer las medidas necesarias para reducir las emisiones de $\mathrm{CO}^{2}$ en un 49\% para 2030 en comparación con 1990.

\section{Estructura y funcionamiento}

La estructura y la organización del Klimaatakkoord refleja en gran medida la propia del Energieakkoord 50 . El Acuerdo finalmente pactado abarca un paquete de más de 600 medidas, que comprenden medidas sectoriales e intersectoriales a las que se han comprometido diversas partes y el propio Gobierno, así como acuerdos entre las partes en los que el Gobierno no tiene un papel activo. Concretamente, el Acuerdo interviene en cinco macro áreas, sobre las cuales han trabajado cinco grandes grupos de trabajo sectoriales: electricidad, entorno construido, industria, agricultura y uso del suelo, y movilidad 5152.

El Gobierno está a cargo de la dirección del Acuerdo, mientras que el Ministerio de Asuntos Económicos y Clima y el SER han sido los encargados de facilitar y mover los hilos del Acuerdo y de las negociaciones en los diferentes grupos de trabajo. Cada mesa sectorial ha sido dirigida por un presidente, responsable de la organización de la mesa y de la forma en que las partes hayan pactado acuerdos internos en el seno de la mesa. El presidente de cada mesa es

\footnotetext{
${ }^{49}$ Página web del Rijksoverheid, <https://www.rijksoverheid.nl/onderwerpen/klimaatakkoord/watis-het-klimaatakkoord> [Última consulta: 18/10/2019].

50 Huelga repetir que el Klimaatakkoord es, en nuestra opinión, por algunos aspectos, la continuación del Acuerdo energético, puesto que, en cuanto a la vertiente energética, se basa en los resultados del Energieakkoord. Por este motivo, como se ha adelantado, se está procediendo con la integración del Energieakkoord en el Klimaatakkoord.

51 Acerca de la composición de las mesas sectoriales, consúltese la página web del Klimaatakkoord "Samenstelling sectortafels Klimaatakkoord bekend", <https://www.klimaatakkoord.nl/organisatie/nieuws/2018/03/20/samenstelling-sectortafelsklimaatakkoord-bekend> [Última consulta: 11/10/2019].

${ }^{52}$ Además, tuvo gran importancia la labor de los grupos de trabajo para financiación, mercado laboral, educación y conocimiento e innovación. Se trata de grupos que han abarcado temas intersectoriales, que deben implementarse en las áreas indicadas y que tienen que garantizar la coherencia de las medidas emprendidas en cada sector. Véase Harold Koster, "Het ontwerp klimaatakkoord", Bedriffsjuridische berichten, 3, 2019. Acerca de las medidas sectoriales, véase la página web del Rijksoverheid "Sectoroverstijgende maatregelen" $<$ https://www.rijksoverheid.nl/onderwerpen/klimaatakkoord/sectoroverstijgende-maatregelen> [Última consulta: 11/10/2019].
} 
miembro del Klimaatberaad, o Consejo del Clima, la mesa general de negociaciones. El Klimaatberaad es un órgano consultivo compuesto por los presidentes de las mesas sectoriales, por representantes de las organizaciones de la sociedad civil, de los gobiernos territoriales y de las ONGs. En la fase de desarrollo y negociación del Acuerdo, el Klimaatberaad ejerció las funciones de coordinación entre las mesas, de supervisión del progreso del proceso y de asegurar que los acuerdos tuvieran apoyo social y administrativo necesario.

Respecto a la implementación del Acuerdo, el rol del Klimaatberaad resulta fundamental para garantizar la coherencia entre las acciones en los sectores y los planes climáticos (que se tratarán a continuación), supervisar los cálculos de los planes climáticos y hacer propuestas legislativas y regulaciones para el seguimiento continuo y registro de sendos planes $^{53}$. Debido a la multisectorialidad de las actuaciones, a nivel estatal, se hacen responsables de la implementación del Acuerdo a cuatro ministerios: el Ministerio de Asuntos Económicos y Clima (Economische Zaken en Klimaat), en relación con las actuaciones en materia de electricidad e industria; el Ministerio de Interior (Binnenlandse Zaken), para lo referente al entorno urbano; el Ministerio de Agricultura, Naturaleza y Calidad de los Alimentos (Landbouw, Natuur en Voedselkwaliteit), para la agricultura y el uso del suelo; y el Ministerio de Infraestructura y Gestión del Agua, para la movilidad (Infrastructuur en Waterstaat).

Para la implementación y el control de los resultados del Klimaatakkoord, se prevé que las partes que se han comprometido con los acuerdos participen en las Overleg per sector, sesiones de implementación sectoriales, bajo la responsabilidad de los ministerios correspondientes. Además de las citadas sesiones, el Ministerio de Asuntos Económicos y Clima es el competente para instituir y presidir el Overkoepelend overleg, un órgano de seguimiento cuyo objetivo es analizar los progresos en los diferentes sectores y garantizar la coherencia del Acuerdo durante toda la fase de implementación.

En cuanto al seguimiento y la publicidad del Acuerdo, sigue publicándose un informe anual sobre los progresos de la implementación por parte de la ya citada

53 Véase la página web del Klimaatakkoord acerca del "Klimaatberaad", <https://www.klimaatakkoord.nl/organisatie/klimaatberaad> [Última consulta: 11/10/2019]. 
Agencia de Evaluación Ambiental de los Países Bajos; dicho informe, denominado Klimaat-en Energieverkenning (KEV) sustituye el anterior NEV. A esto cabe añadir un conjunto de indicadores del proceso de ejecución, accesibles a través de una plataforma en línea, mediante el cual las Overleg per sector pueden seguir el avance en las medidas y acuerdos por cada área determinada ${ }^{54}$.

Finalmente, el gobierno informará anualmente a las Cámaras y al Consejo de Estado sobre la evolución de la política climática a través de la Klimaatnota o Memorandum Climático ${ }^{55}$, que se basará en los datos de resultados recogidos por el KEV. A esto cabe añadir que, al menos una vez cada cinco años, el Gobierno debe revisar la política climática y redactar el Klimaatplan, un Plan Climático para los siguientes diez años, tal como se ha establecido en la Klimaatwet, o Ley del Clima. Estos instrumentos se analizarán a continuación.

\section{2. "Klimaatakkoord", "Klimaatwet" y "Klimaatplan"}

El 1 de septiembre de 2019, a pocos meses de la firma del Klimaatakkoord, entró en vigor la Klimaatwet, la Ley de Clima neerlandesa ${ }^{56}$. Resulta interesante analizar en qué difieren y qué relación existe entre uno y otra teniendo presente que mientras el Klimaatakkoord es un documento político, la Klimaatwet es una ley. Sin embargo, los dos resultan estrictamente conectados entre ellos y casi interdependientes. En primer lugar, en ambos se establece el mismo objetivo: reducir las emisiones de gases de efecto invernadero en un 49\% en 2030 (en el

54 Véase la página web del Klimaatakkoord "Uitvoering van het Klimaatakkoord", <https://www.klimaatakkoord.nl/organisatie/monitoring-borging-governance> [Última consulta: 12/10/2019]. En la citada página web se especifica que "Las partes que se sentaron a la mesa durante las negociaciones y respaldaron el Acuerdo serán invitadas a participar en las consultas de implementación por sector organizadas por los ministerios. Por ejemplo, una consulta de implementación sectorial sobre el entorno construido se instituirá bajo la dirección del Ministerio de Interior y una consulta de implementación sobre electricidad, bajo la dirección del Ministerio de Asuntos Económicos y Clima. Cada consulta sectorial funciona de acuerdo con la Agenda de Implementación que el ministerio responsable elabora sobre la base del Acuerdo Climático" (trad. propia).

${ }^{55}$ Edwin Van Gastel, "Klimaatberaad: Klimaatakkoord moet dubbel verankerd worden", 4 de junio de 2019, SolarMagazine (web) <https://solarmagazine.nl/nieuws-zonneenergie/i18640/klimaatberaad-klimaatakkoord-moet-dubbel-verankerd-worden>. [Última consulta: 12/10/2019].

${ }^{56}$ Klimaatwet, Ley del 2 de julio de 2019, que establece un marco para el desarrollo de políticas dirigidas a la reducción irreversible y de las emisiones holandesas de gases de efecto invernadero para limitar el calentamiento global y el cambio climático. Consultable en: <https://zoek.officielebekendmakingen.nl/stb-2019-253.html> [Útima consulta: 27/12/2019]. 
art. 2 Klimaatwet se añade el objetivo de reducción de emisiones de un 95\% en 2050) en comparación con los niveles de 1990. Se trata, por lo tanto, de previsiones no solamente políticas sino también legalmente vinculantes, aunque sea solamente para el Gobierno.

La Klimaatwet, de tan solo diez artículos, curiosamente no contiene obligaciones ni para los otros entes territoriales ni para los actores sociales. El único responsable es el Gobierno central. Sin embargo, el capítulo cuarto hace referencia a la necesidad de la participación de los entes locales y actores sociales: "para la implementación de esta Ley y el logro de los objetivos mencionados en el art. 2, el Ministro consultará los órganos administrativos de las provincias, juntas de agua, municipios y otras partes relevantes"; asimismo "el Ministro promueve la celebración de acuerdos con las partes para lograr los objetivos mencionados en el art. 2 a través de consultas" (art. 8.1 y 8.3). Como subraya Barnhoorn, "[l]a responsabilidad de promover la participación y la consulta recae en el Ministro. Esto expresa el principio general de que el gobierno involucra a la sociedad en la preparación e implementación de las regulaciones" 57 .

Analizando la Ley, observamos que no se concretan de manera alguna las medidas que el Gobierno tiene que llevar a cabo para la consecución de los objetivos, que, en cambio, como hemos analizado, se encuentran detalladas en el Klimaatakkoord. De hecho, la Klimaatwet se tramitó simultáneamente con las negociaciones del Klimaatakkoord, por lo cual hubiera sido imposible trasladar los resultados del Acuerdo en la Ley. Por lo tanto, se puede afirmar que la Klimaatwet es simplemente una Ley marco que establece unas obligaciones de resultado para el Gobierno central - y sólo para éste - y que confiere al mismo un margen de negociación para pactar políticamente medidas sustantivas con los actores sociales, tal como se ha analizado en el Klimaatakkoord.

Cabe señalar que la aprobación de la Klimaatwet ha sido acogida con opiniones discordantes y muchas críticas. El texto finalmente aprobado, enmendado ampliamente, es mucho más modesto que la propuesta original y revela una gran

57 Lianne Barnhoorn, "Participatie verankerd in nieuwe Klimaatwet", Pels Rijcken. Traducción propia. Disponible en: <https://blogklimaatenergie.nl/2019/06/04/participatie-verankerd-innieuwe-klimaatwet/> [Última consulta: 20/05/2020]. 
flexibilidad para que el Gobierno establezca y modifique la hoja de ruta a seguir para lograr los objetivos establecidos. Además, se recrimina que se trate de una Ley vacía, sin contenido, y que no establezca sanciones por la no consecución de los objetivos. Sin embargo, el Gobierno ha replicado que no es necesario que la Ley establezca sanciones, ya que "sin ley también se puede demandar al Estado por no cumplir con los objetivos climáticos" 58 , como ha demostrado la Sentencia del caso Urgenda.

La Klimaatwet establece la obligación para el Gobierno de aprobar un plan climático, el Klimaatplan, de nuevo un instrumento de naturaleza política, con una vigencia decenal, que debe ser sometido a consulta pública e informado por el Consejo de Estado.

El contenido del Klimaatplan ${ }^{59}$, que corresponde en buena medida al Plan Nacional Integrado de Energía y Clima $^{60}$ se detalla en el art. 3 de la Klimaatwet. Antes de su adopción por parte del Ministro de Asuntos Económicos y Clima, el Plan deberá ser presentado a las Cámaras, para que lleven a cabo la verificación parlamentaria sobre la conveniencia y viabilidad de contenido del mismo. El plan climático se evaluará y redefinirá al menos una vez cada cinco años; cada dos años después de la adopción se informará a las Cámaras del progreso en la implementación y, en caso necesario, a la luz de los resultados, se tomarán, por parte del Gobierno, las medidas adicionales que sean precisas (art. 4). Además, cada año el Ministro de Asuntos Económicos y Clima deberá remitir a las Cámaras y al Consejo de Estado la Klimaatnota, un Memorandum climático que recoja la evolución de la política climática en relación con el plan (art.7).

Una cuestión que nos parece interesante subrayar es la inversión de roles de la regulación climática respecto a los acuerdos. La Klimaatwet impone simplemente

58 Edo van der Goot, "Eerste Kamer stemt in met Klimaatwet: Dit zijn de belangrijkste punten", de 28 de mayo de 2019, Nu.nl (web) <https://www.nu.nl/politiek/5912553/eerste-kamer-stemt-inmet-klimaatwet-dit-zijn-de-belangrijkste-punten.html>. [Última consulta: 25/10/2019] (traducción propia).

${ }_{59}$ El primer Klimaatplan (2021-2030) es consultable en <https://www.rijksoverheid.nl/documenten/beleidsnotas/2020/04/24/klimaatplan-2021-2030> [Última consulta: 20/05/2020].

60 De acuerdo con el Reglamento (UE) 2018/1999 del Parlamento Europeo y del Consejo, de 11 de diciembre de 2018, todos los Países miembros de la Unión Europea deben dotarse de un Plan Nacional Integrado de Energía y Clima. El Integraal Nationaal Energie- en Klimaatplan 20212030 (INEK), adoptado en noviembre de 2019, es consultable en: <https://www.rijksoverheid.nl/documenten/rapporten/2019/11/01/integraal-nationaal-energie-enklimaatplan> [Ültima consulta: 21/12/2019]. 
una obligación de resultado para el Gobierno y representa un marco para que el Gobierno, a través de los acuerdos, pueda pactar metas más específicas y medidas concretas que permitan cumplir con los objetivos establecidos en dicha Ley. Acuerdos que serán la base para la adopción o modificación de leyes sectoriales.

Según Van 't Lam, siendo los acuerdos instrumentos políticos, el contenido de los mismos no podrá ser cuestionado legalmente ${ }^{61}$; pero sí las eventuales leyes sectoriales de desarrollo de los acuerdos.

\section{El "Klimaatakkoord" y el paquete de "medidas Urgenda"}

En referencia a la relación entre el Klimaatakkoord y el caso Urgenda ${ }^{62}$, cabe poner de manifiesto que el Klimaatakkoord no estaba pensado, de entrada, como un plan de trabajo del Gobierno para dar respuesta al conocido caso Urgenda. De hecho, el año de referencia para el cumplimento del Acuerdo es el 2030, mientras que la reducción de emisiones reclamada en el caso Urgenda se refería al 2020. Además, cuando empezaron las negociaciones del Acuerdo Climático, en febrero de 2018 , la sentencia de apelación aún no había sido dictada ${ }^{63}$. Sin embargo, en octubre 2018, el fallo de la sentencia de apelación confirmaba la responsabilidad del Estado de proteger a los ciudadanos contra los efectos del cambio climático e instaba a los Países Bajos a reducir sus emisiones de gases de efecto invernadero en 2020 en al menos un 25\% en comparación con 1990.

La PBL, en enero de 2019, determinó que la ejecución del Acuerdo Climático podría lograr una reducción de gases de efecto invernadero en 2020 de

\footnotetext{
61 Valérie van 't Lam, "Aangenomen Klimaatwet: een belangrijke symboolfunctie geformaliseerd", Stibbe. Disponible en: <https://www.stibbe.com/en/news/2019/june/aangenomen-klimaatweteen-belangrijke-symboolfunctie-geformaliseerd>. [Última consulta: 25/10/2019].

62 Acerca del caso Urgenda, véanse, entre todos, K. J. Graaf y J. H Jans, "The Urgenda Decision: Netherlands Liable for Role in Causing Dangerous Global Climate Change", Journal of Environmental Law, 27.3 (2015), pp. 517-27. Jonathan Verschuuren, "The State of the Netherlands vs Urgenda Foundation : The Hague Court of Appeal upholds judgment requiring the Netherlands to further reduce its greenhouse gas emissions", Review of European, Comparative and International Environmental Law (RECIEL), 28 (2019), pp. 94-98. Noel Rodríguez García, «Responsabilidad del Estado y cambio climático: el caso Urgenda c. Países Bajos», Revista Catalana de Dret Ambiental, 7.2 (2016). Teresa Parejo Navajas, «La victoria de Urgenda: el inicio de la lucha judicial frente al cambio climático", Revista española de derecho administrativo, 177 (2016), pp. 259-79.

63 La sentencia de apelación es de octubre de 2018. Para consultar la cronología del caso Urgenda, véase <https://www.urgenda.nl/en/themas/climate-case/climate-case-explained/> [Última consulta: 15/01/2020].
} 
aproximadamente el $21 \%$ en comparación con 199064. Una estimación insuficiente para cumplir con el fallo de la sentencia de apelación del caso Urgenda. Tras esta sentencia, y simultáneamente a la adopción del Klimaatakkoord, el Ministro de Asuntos Económicos y Clima, anunciaba una serie de medidas de ejecución (llamadas "medidas Urgenda" ${ }^{65}$ ) para intentar reducir las emisiones en 2020 y cumplir así con las exigencias del pronunciamiento judicial. Es en este momento que el Klimaatakkoord y el caso Urgenda convergen, dada la decisión del Gobierno de dar cumplimento a la sentencia del caso Urgenda junto con las medidas derivadas del Acuerdo Climático. En efecto, el paquete de medidas necesario para dar cumplimento al fallo del caso Urgenda tiene inevitablemente un impacto en el Klimaatakkoord y coadyuva al diseño de la hoja de ruta del mismo; puesto que el objetivo de ambos es la reducción de emisiones de gases de efecto invernadero, aunque sobre una escala temporal diferente.

La Carta al Parlamento sobre la implementación de la sentencia Urgenda, de 28 de junio de 2019, contiene, entre otras medidas, el cierre anticipado de la central eléctrica de Hemweg (a partir del 1 de enero de 2020), así como la reducción del óxido de nitrógeno y el impulso, a través de medidas de fomento, del ahorro energético en hogares, y de reducción de $\mathrm{CO}_{2}$ en la industria ${ }^{66}$.

Finalmente, en diciembre de 2019, tras la decisión histórica de la Hoge Raad, la Corte de Casación neerlandesa ${ }^{67}$, de confirmar las sentencias de primera y segunda instancia, el Gobierno se comprometió a elaborar medidas adicionales, en cumplimento del fallo judicial, antes del 1 de abril de $2020^{68}$. En virtud de lo

\footnotetext{
64 Véase el informe de la PBL "Kortetermijnraming voor emissies en energie in 2020", de 25 de enero de 2019. Disponible en <https://www.pbl.nl/publicaties/kortetermijnraming-voor-emissiesen-energie-in-2020> [Última consulta: 21/05/2020].

65 URGENDA'-maatregelen. Véase el informe del PBL "Het Klimaatakkoord: effecten en aandachtspunten", disponible en: <https://www.pbl.nl/publicaties/het-klimaatakkoord-effectenen-aandachtspunten> [Última consulta: 17/01/2020].

${ }^{66}$ Para todas las medidas, véase la Carta del Parlamento que implementa la sentencia Urgenda, de 28 de junio de 2019, Documento parlamentario 32813 n. 341 (Kamerbrief Uitvoering Urgendavonnis, 28 juni 2019, $32813 \mathrm{nr}$. 341), consultable en: https://zoek.officielebekendmakingen.nl/kst32813-341.html [Última consulta: 20/12/2019].

67 ECLI:NL:HR:2019:2007, Hoge Raad, 19/00135. Para consultar en inglés la sentencia de la casación neerlandesa acerca del caso Urgenda, de 20 de diciembre de 2019, véase <https://uitspraken.rechtspraak.nl/inziendocument?id=ECLI:NL:HR:2019:2007> (Fecha última consulta: 18/01/2020).

68 Documento parlamentario 32813 N. 442, de 20 de diciembre de 2019, consultable en < https://zoek.officielebekendmakingen.nl/kst-32813-442.html> y Documento parlamentario 32813
} 
cual, el 24 de abril de 2020, el Gobierno ha presentado un paquete de "medidas Urgenda" adicionales, a corto plazo, que las propias autoridades consideran también útiles para la recuperación económica sostenible y para super la crisis causada por la pandemia de la Covid-19. Las principales son: la reducción de la producción de las centrales eléctricas de carbón ${ }^{69}$; la conversión acelerada de instalaciones, la optimización de los procesos o instalaciones técnicas con bajo contenido de $\mathrm{CO}_{2}$ en diferentes sectores industriales; la financiación adicional de medidas para el ahorro de energía doméstica y para proyectos de energía renovable en las pymes ${ }^{70}$.

\section{CONSIDERACIONES ANALÍTICAS}

Tras el análisis descriptivo anterior, nos parece relevante considerar las características positivas y negativas de los Akkoords y, en concreto, de los dos analizados, a saber, el Klimaatakkoord y el Energieakkoord.

En este sentido, ya podemos afirmar ab initio que, en nuestra opinión, los acuerdos representan, en general, un instrumento que evidencia significativos aspectos positivos, que parecen reforzarse si los consideramos en relación con las políticas de cambio climático y de transición energética. Entre los que destacamos, la coordinación y colaboración para la formulación de políticas consensuada con los gobiernos locales, la búsqueda de aceptación social y de participación activa de los ciudadanos y, finalmente, la importancia del apoyo de los actores sociales. Ahora bien, es preciso poner de manifiesto que los Akkoords presentan, así mismo, múltiples factores problemáticos, entre los cuales destacan sobre todo una serie de aspectos, íntimamente relacionados entre ellos y con el apoyo de los actores sociales y la presencia de grupos de interés en las negociaciones. Todos ellos se considerarán a continuación.

N. 448, de 18 de febrero de 2020, consultable en < https://zoek.officielebekendmakingen.nl/kst32813-448.html> [Última consulta: 20/05/2020].

${ }^{69}$ Por el momento, no se prevé el cierre de ninguna central eléctrica de carbón adicional en 2020 , respecto a lo establecido en la Ley de prohibición del carbón para la producción de electricidad (Wet verbod op kolen bij elektriciteitsproductie), en vigor desde el 20 de diciembre de 2019. Disponible en <https://zoek.officielebekendmakingen.nl/stb-2019-493.html> [Última consulta: 20/05/2020].

70 Documento parlamentario 32813 N. 496, de 24 de abril de 2020. Disponible en <https://zoek.officielebekendmakingen.nl/kst-32813-496.html> [Última consulta: 20/05/2020]. 


\section{Coordinación entre niveles de gobierno y administraciones}

La configuración del descrito modelo de governance intenta harmonizar objetivos y mecanismos, buscar compromisos y equilibrar los intereses de las partes, así como solventar el aislamiento y la falta de coherencia en la formulación de políticas públicas de los diferentes niveles de gobierno (governance colaborativa y multinivel).

Respecto a la formulación de políticas consensuadas con los niveles de gobierno subestatales, cabe matizar que no se está haciendo referencia aquí a políticas decididas por el Gobierno central e implementadas por los entes locales, ni tampoco al "controvertido" mecanismo del medebewin ${ }^{71}$. Los Acuerdos climático y energético van más allá, dejando autonomía decisional a los diferentes niveles de administración. Sin embargo, no se trata de una autonomía sobre los targets, fijados a nivel nacional, sino sobre los mejores mecanismos para lograrlos.

Por un lado, como se ha tenido ocasión de observar, se ha garantizado que los entes locales, a través de las organizaciones representativas, participen en las mesas de negociación de los acuerdos. Por el otro, Interbestuurlijk programma (IBP), el Acuerdo interadministrativo ${ }^{72}$ adoptado el 14 de febrero de 2018 entre

71 El mecanismo del medebewin, que emerge en el párrafo segundo del art. 124 Constitución Neerlandesa, y que podríamos traducir como "co-gobierno" o "administración conjunta", está pensado como mecanismo de co-decisión y co-implementación de políticas entre los niveles de gobierno. Sin embargo, si bien proclamado como mecanismo de cooperación, se trata en realidad de la implementación descentralizada, por parte de municipios y provincias, de muchas políticas gubernamentales, decididas exclusivamente por el gobierno central, sin posibilidad o con muy escasa posibilidad de libertad política para las autoridades descentralizadas. En el Report del Congress of Local and Regional Authorities de 2014 se describe el citado mecanismo como "a feature of Dutch local self-government whereby local and regional governments and other public authorities carry out tasks and make regulations as required by higher authorities (the central government, most of the time)". En estos términos, el Medebewind podría llegar a limitar la autonomía de municipios y provincias. Esta tensión entre la autonomía local y el Medebewind es presente en la mayoría de las políticas públicas neerlandesas. Véase Artur Torres Pereira y JeanPierre Liouville, Report on Local and regional democracy in the Netherlands -CG(26)7FINAL, 2014. Disponible en: $<$ https://search.coe.int/congress/pages/result_details.aspx?objectid=090000168071a7f4\#_ftnref $11>$. [Última consulta 21/07/2019]. Acerca del citado mecanismo, véanse también Wytze Van Der Woude, "De Grondwet - Artikel 124 - Autonomie en Medebewind", Wetenschappelijk Comentaar op de Nederlandse Grondwet. Disponible en: <https://www.nederlandrechtsstaat.nl/module/nlrs/script/viewer.asp?soort=commentaar\&artikel= 124> [Última consulta: 21/07/2019]. Linze Schaap, "Decentrale autonomie ?", Rapportage ter voorbereiding op het onderzoek van de Raad van Europa naar de staat van de decentrale autonomie in Nederland, 2012, p. 4. Disponible en: <https://www.vng.nl/files/vng/20121024_pre_monitoring_report_schaap.pdf> [Última consulta: 21/07/2019].

$72 \quad$ Disponible en https://vng.nl/sites/default/files/brieven/2018/attachments/programmastart_ibp_0_0.pdf [Última consulta: 28/09/2019]. 
los gobiernos centrales y territoriales, incluye un apartado específico acerca del cambio climático (Samen voor het klimaat), puesto que "la división de poderes entre el gobierno central y las autoridades locales y regionales no debe hacer que los gobiernos interfieran entre sí, sino que se fortalezcan mutuamente"73. En el anexo primero del programa $\mathrm{IBP}^{74}$ se hace referencia a los métodos y mecanismos - aunque no se detallan - para posibilitar esta división de tareas, respecto a tres submaterias específicas: mitigación climática, adaptación climática y economía circular. Entre todos, destacamos la necesidad de celebrar sesiones de trabajo constantes entre los diferentes niveles administrativos, consagrada también en la Klimaatwet (art. 8.1), para tratar la ejecución y consecución de los objetivos del Klimaatakkoord.

Además, el programa IBP reserva un cometido importante a las Regionale Energiestrategie (RES), las Estrategias Energéticas Regionales ${ }^{75}$, que son un ejemplo emblemático de la coordinación entre los diferentes niveles institucionales y entre éstos, las empresas y los actores sociales en los ámbitos de la planificación eléctrica ${ }^{76} \mathrm{y}$ del entorno urbano ${ }^{77}$. Una doble función que merece un análisis detenido, que ofreceremos a continuación.

En ámbito nacional, a través del Plan Nacional RES, se han delimitado - por iniciativa de municipios, provincias y juntas de agua -30 áreas regionales ${ }^{78}$, en función de características comunes de los citados entes locales. Estas áreas regionales desempeñarán un importante papel en la generación sostenible de energía on-shore. Concretamente las autoridades locales de cada región, en

\footnotetext{
73 Ibidem, p. 11 (traducción propia).

74 Ibidem, pp. 37 y ss.

75 Véase el apartado del Klimaatakkoord acerca de las RES. Disponible en: <https://www.klimaatakkoord.nl/binaries/klimaatakkoord/documenten/publicaties/2019/06/28/kli maatakkoord-hoofdstuk-res/klimaatakkoord-d7+RES.pdf> [Última consulta: 12/10/2019].

${ }^{76}$ Acerca del objetivo, de las medidas y de las actuaciones concretas en materia de electricidad, véase la página web del Klimaatakkoord: <https://www.klimaatakkoord.nl/elektriciteit> y el apartado c5 del Klimaatakkoord, consultable en: <https://www.klimaatakkoord.nl/binaries/klimaatakkoord/documenten/publicaties/2019/06/28/kli maatakkoord-hoofdstuk-elektriciteit/klimaatakkoord-c5+Elektriciteit.pdf> [Última consulta: 12/10/2019].

${ }^{77}$ Acerca del objetivo, de las medidas y de las actuaciones concretas en relación con el tema del entorno construido, véanse las páginas web del Klimaatakkoord: <https://www.klimaatakkoord.nl/gebouwde-omgeving> <https://www.klimaatakkoord.nl/binaries/klimaatakkoord/documenten/publicaties/2019/06/28/kli maatakkoord-gebouwde-omgeving-in-het-kort/klimaatakkoord+GO+in+het+kortV2.pdf> [Última consulta: 12/10/2019] (traducción propia).

78 Véase la página web "Regio's op de kaart", <https://www.regionaleenergiestrategie.nl/kaart+doorklik/default.aspx> [Última consulta: 13/10/2019].
} 
coordinación entre ellas y con la participación de la población, determinarán qué objetivos energéticos deben alcanzarse en cada región, en qué plazos y cómo se pretende lograrlos. La suma de todas las RES debe contribuir a lograr el objetivo nacional (35 TWh de energía renovable en 2030). Por este motivo, todos los borradores de las RES serán enviados a la Agencia de Evaluación Ambiental (PBL) que los evaluará, separadamente y en su conjunto, y los reenviará a los entes locales para su revisión. En el caso de que los compromisos de las RES en el conjunto resulten insuficientes para lograr el objetivo nacional, o si no se ha podido llegar a un consenso acerca de una RES o ésta no se haya podido llevar a cabo, se intentará resolver esta situación mediante la cooperación administrativa y reuniones entre los entes locales del área regional correspondiente y, de no lograrse, intervendrá el comité directivo del Programa Nacional RES.

En este sentido, podríamos definir las RES como un "instrumento que utiliza la participación social para tomar decisiones regionales ${ }^{79}$ en los ámbitos de la generación de electricidad renovable, de la transición aplicada a las redes urbanas de calor y de la infraestructura de almacenamiento y energía"80. Su valor añadido reside en que se trata de "una forma de organizar la cooperación entre todos los actores regionales (institucionales y organizaciones de la sociedad civil) en preparación para proyectos concretos que surgen de la estrategia" ${ }^{81}$.

Además de fomentar el apoyo público y aumentar la coordinación entre Administraciones públicas, las RES son también importantes instrumentos de

\footnotetext{
${ }^{79}$ Es preciso puntualizar que las regiones neerlandesas entrarían en la categoría que Berger y Pohoryles definen como "functional or polar región" (regiones definidas en base a la función que llevan a cabo en el área espacial de referencia) y que difieren de las "administrative and programminig regions" (regiones entendidas como entidades político-administrativas). Véase Gerald Berger y Ronald J. Pohoryles, «Policy Integration and Capacity-Building in Regional Sustainable Development: Analysis of Experiences in Europe», en 2004 Berlin Conference on the Human Dimension of Global Environmental Change, 2006, pp. 1-22. Citados en Michela Catenacci, «Environmental policy integration at Regional and Local Levels: setting the problem into context», en Governance for the Environment: A Comparative Analysis of Environmental Policy Integration, ed. Alessandra Goria, Alessandra Sgobbi, y Ingmar von Homeyer (Edward Elgar Publishing, 2010), pp. 45 ss.

80 Traducción propia, Fuente: página web "Wat is de Regionale Energie Strategie (RES)?", disponible en: <https://www.regionale-energiestrategie.nl/vragen/vragen++algemeen+res/1275417.aspx> [Última consulta: 12/10/2019].

81 lbidem. (traducción propia).
} 
planificación territorial de la región y de los municipios ${ }^{82}$. La integración espacial de la generación de energía sostenible es una de las competencias más relevantes atribuidas a provincias y municipios en el ámbito del Klimaatakkoord. Desde un punto de vista formal, la RES es un documento programático que describe las estrategias que la región va a desarrollar para determinar y alcanzar los objetivos energéticos regionales fijados ${ }^{83}$, con un horizonte de 2030 y con una mirada al 2050. Sin embargo, es necesario que la RES sea coherente y se integre con los demás instrumentos programáticos y administrativos previstos en la Wet ruimtelijke ordening, la Ley de Planificación territorial y en la futura Omgevingswet, Ley Ambienta| ${ }^{84}$, sobre todo en relación con los planes ambientales (Omgevingsbeleid -Omgevingsplannen), con los programas ambientales (Omgevingsprogramma) provinciales y municipales así como con las autorizaciones ambientales de las instalaciones de energía y de las infraestructuras energéticas.

En la actualidad, si bien a diferentes ritmos, en cada región, los entes locales están trabajando para la elaboración de la RES correspondiente, junto con el mundo empresarial, las organizaciones sociales, los operadores de red y los residentes ${ }^{85}$. El objetivo es que cada RES esté confeccionada a medida para su propia región y reúna los puntos de vistas de los diferentes actores políticos, económicos y sociales, que, de esta manera, adquirirán una mayor responsabilidad a la hora de implementar las estrategias diseñadas. Así pues, "[D]ado que cada región se enfrenta a una situación y necesidades diferentes, es importante no imponer el Acuerdo Nacional sobre el Clima desde arriba, sino dejar que las autoridades locales, las empresas de la región, las organizaciones

\footnotetext{
82 Véase la página web "Overzicht energietransitie in de gebouwde omgeving" de la VNG: $<$ https://vng.nl/artikelen/overzicht-energietransitie-in-de-gebouwde-omgeving > [Última consulta: 17/10/2019].

83 "Wat is de Regionale Energie Strategie (RES)?", cit. (traducción propia).

${ }^{84}$ La nueva Ley Ambiental (Omgevingswet), que entrará en vigor en 2022, reemplazará a la Ley de Planificación Territorial. Se puede consultar el texto de la Omgevingswet (Wet van 23 maart 2016, houdende regels over het beschermen en benutten van de fysieke leefomgeving (Omgevingswet)

en: $<$ https://www.omgevingswetportaal.nl/binaries/omgevingswetportaal/documenten/publicaties/20 16/03/23/de-omgevingswet-staatsblad/de-omgevingswet-in-het-staatsblad.pdf>. Acerca de los citados instrumentos, véase también la página web de la VNG "Visie, plan, vergunning en programa", <https://vng.nl/onderwerpenindex/omgevingswet/omgevingsvisie-omgevingsplanvergunning-en-programma> [Última consulta: 12/10/2019].

${ }^{85}$ Véase el apartado "D5 Bevordering draagvlak" y "D6 Ruimte" del Klimaatakkoord.
} 
sociales y los propios ciudadanos tomen la iniciativa en lo que es más apropiado en su región"86.

\section{Búsqueda de la aceptación social y de la participación activa de los ciudadanos}

Obtener el apoyo y contar con la participación de los ciudadanos es uno de los retos más importantes y complicados del Klimaatakkoord. VERDAAS evidencia que, aunque la transición sea una tarea compleja y la primera reacción natural sea simplificarla, sin embargo, se debe intentar revertir esta tendencia a simplificar de forma lineal e involucrar a los ciudadanos, si se quiere obtener un resultado social óptimo ${ }^{87}$.

Según los resultados del Informe "Klimaatakkoord 2018. Maatschappelijke acceptatie en participatie"88 la participación de los ciudadanos se requiere en tres fases diferentes: en primer lugar, durante el proceso de negociación y redacción del Acuerdo89; en segundo lugar, en la elaboración de la RES; y, en tercer lugar, en la fase de desarrollo de los planes que implementarán las RES, con participación a nivel de municipio y de barrio. A éstas cabe añadir una cuarta fase: la participación directa en los proyectos.

86 "Omdat elke regio te maken heeft met een andere situatie en met andere behoeften, is het van belang het nationale Klimaatakkoord niet van bovenaf op te leggen, maar lokale overheden, bedrijven in de regio, maatschappelijke partijen en burgers zelf het voortouw te laten nemen in wat er in hun regio het beste past" (traducción propia). Antwoorden op vragen lokale bestuurders, 2018 (Documento de trabajo). Disponible en: <https://www.klimaatakkoord.nl/binaries/klimaatakkoord/documenten/publicaties/2018/11/07/ant woorden-op-vragen-lokale-

bestuurders/181112+Antwoorden+op+vragen+lokale+bestuurders.pdf>. [Última consulta: 13/10/2019] (traducción propia).

87 Trad. Propia. "De opgave is complex en de eerste reactie die we van nature hebben is om de opgave te vereenvoudigen. Deze neiging om lineair te simplificeren moeten we echter onderdrukken als we willen gaan voor een optimaal maatschappelijk resultaat". Johannes Cornelis Verdaas, "Energie \& gebiedsontwikkeling: een winnende combinatie" <http://files.m11.mailplus.nl/user31100268/16112/Essay-Co_Verdaas.pdf> [Última consulta: 19/10/2019].

88 Roel Woudstra et al., Klimaatakkoord 2018. Maatschappelijke acceptatie en participatie, 2018 $<$ https://www.klimaatakkoord.nl/themas/draagvlak-en-

participatie/documenten/rapporten/2018/07/02/eindrapport-raadplegen-burgernetwerken>

[Última consulta: 19/10/2019]. Asimismo, véanse las consideraciones contenidas en el Integraal Nationaal Energie- en Klimaatplan 2021-2030 (INEK), pp. 19 ss. <https://www.rijksoverheid.nl/documenten/rapporten/2019/11/01/integraal-nationaal-energie-enklimaatplan> [Última consulta: 21/12/2019].

89 Véase la página web del Klimaatakkoord "Hoe worden burgers betrokken bij het Klimaatakkoord?" <https:/www.klimaatakkoord.nl/participatie/vraag-en-antwoord/hoe-wordenburgers-betrokken-bij-het-klimaatakkoord> [Última consulta: 19/10/2019]. 
En la primera fase, de negociación del Acuerdo, la participación de los ciudadanos se ha llevado a cabo a través de sesiones y reuniones públicas. Sin embargo, no se prevé la participación directa de ciudadanos (o por lo menos una representación de los mismos) en las mesas de trabajo. Por el contrario, parece que se está prestando más atención a la participación ciudadana en las fases siguientes.

En cuanto a las RES, una de las medidas más relevantes contenida en ellas, referida al entorno urbano, es, por ejemplo, que los edificios se desconecten de la red de gas natural; tarea en la que los municipios asumen un papel central ${ }^{90}$. Específicamente, cada municipio está redactando actualmente, junto con las demás autoridades locales, con los propietarios, los arrendatarios, los operadores de redes, su sistema de redes de calor, a través de la Transitievisie Warmte. Se trata de un documento programático en el que se indican las directrices a seguir, las propuestas concretas a desarrollar, un mapa del municipio dividido por distritos con las actuaciones previstas y el tiempo estimado para la realización de las mismas. Se trata de planes orientados a nivel de Wijken, o barrio, con un enfoque totalmente bottom-up y que sitúan en el centro la participación activa de los vecinos de los mismos ${ }^{91}$, para actuar con su perfil sociocultural.

Involucrar a los ciudadanos significa, en primer lugar, asegurarse de que reciban una información transparente, detallada y fiable, para que se pueda incrementar

\footnotetext{
90 Sin embargo, acerca de esta cuestión, la PBL critica el Gobierno por no ayudar suficientemente a los municipios, con mayores recursos económicos y otorgando más poderes en esta tarea. La PBL subraya que los recursos limitados de los municipios son en marcado contraste con la complejidad de la tarea: "El Acuerdo sobre el Clima otorga a los municipios un papel central de coordinación en el enfoque de distritos sin gas natural. Esto parece sensato porque los municipios conocen mejor la situación local y están más cerca de los ciudadanos. Esto da a los municipios una gran responsabilidad para incluir y apoyar a los ciudadanos en la transición a los distritos de calor, tarea que puede tener un impacto en el apoyo público de la política climática holandesa en su conjunto. El Acuerdo sobre el Clima deja abierta la cuestión de si los municipios recibirán suficientes poderes, capacidad y apoyo para cumplir esta función". Trad. propia. Vid. informe de la PBL "Het Klimaatakkoord: effecten en aandachtspunten", cit., pp. 22-23. Lo mismo resultados se aprecian en el informe de la PBL "Gemeentelijke bestuurskracht en de energietransitie", de 6 de septiembre de 2019. Consultable en <https://www.pbl.nl/publicaties/gemeentelijke-bestuurskracht-en-de-energietransitie> [Última consulta: 20/12/2019].

91 Sobre esta cuestión, vid. Goda Perlaviciute, Lorenzo Squintani, Gido Metz, De mening van inwoners van Vinkhuizen-Noord over een aardgasvrij Vinkhuizen-Noord, Rijksuniversiteit Groningen, 2019. Consultable en <https://www.rug.nl/about-us/collaboration/researchcollaboration/onderzoekenergietransitie/afgeronde-projecten/een-gasvrij-vinkhuizen-noord> [Última consulta: 20/12/2019].
} 
la aceptación social y, por ende, el apoyo a las acciones concretas que se han de desarrollar. Además, la aceptación social es de importancia fundamental para prevenir la creciente resistencia y el obstruccionismo entre la ciudadanía92. En cualquier caso, aceptación social y participación activa son dos caras de la misma moneda, son etapas que se retroalimentan mutuamente, de manera que "si el Klimaatakkoord quiere ser lo más eficaz posible entonces debe contribuir tanto a la aceptación como a la participación"93.

El Klimaatakkoord incluye un apartado relacionado con el apoyo y la aceptación social en que se puede apreciar que "[e]l apoyo y la aceptación [social] pueden lograrse si el proceso de toma de decisiones es transparente y los beneficios y los costes se comparten equitativamente. La distribución justa de costes y beneficios debe interpretarse en un sentido amplio: no sólo desde el punto de vista financiero, sino también, entre otros, espacial y social. Por ejemplo, en el caso de la energía renovable on-shore, esto significa que los ciudadanos y las empresas deben tener la oportunidad de participar en establecer dónde se llevarán a cabo los proyectos $\mathrm{y}$, si es posible, participar también en las ganancias"94. Se desplegarían así una tercera fase, de necesaria participación en la decisión acerca de los proyectos ${ }^{95}$ y una cuarta de participación directa en los mismos ${ }^{96}$.

\footnotetext{
92 Un problema muy acentuado en los Países Bajos es la resistencia pública a la planificación e implantación de parques eólicos por causas diferentes, entre las cuales se encuentra el descontento por la falta de participación efectiva de los vecinos en las ganancias y una notable expansión del sentimiento NIMBY (not in my backyard). Sobre el tema véanse: Sanne Akerboom, "Between Public Participation and Energy Transition: the case of wind farms", 2018, (tesis doctoral); J.W. Co van Zundert, "Duurzame energie en omgevingsrecht", disponible en: <https://www.navigator.nl/thema/1130/duurzame-energie-en-omgevingsrecht>. [Última consulta: 24/10/2019]. Acerca del tema, véase también, Matthijs van Schie, "Provincies in hun maag met windmolens: verzet groeit", de 27 de agosto de 2019, ElSevier Weekblad (web) <https://www.elsevierweekblad.nl/nederland/achtergrond/2019/08/draagvlak-voor-windmolensneemt-steeds-verder-af-705147/>; Koen Nederhof, Edwin Timmer, "Provincies zien enthousiasme voor klimaatminaret afnemen", de 27 de agosto de 2019, De Telegraaf (web) $<$ https://www.telegraaf.nl/nieuws/858941704/provincies-zien-enthousiasme-voorklimaatminaret-afnemen>. [Última consulta: 24/10/2019].

93 "Wil het KA maximaal effectief zijn dan moet het bijdragen zowel aan acceptatie als aan participatie". Traducción propia. Roel Woudstra et al., Klimaatakkoord 2018. Maatschappelijke acceptatie en participatie, cit., 2018, p. 5 (traducción própia).

${ }_{94}$ Traducción propia. Vid. Klimaatakkoord, D5 Bevordering draagvlak, p. 216 (traducción propia). 95 Participatie in beleidsfase. Fuente: <https://www.klimaatakkoord.nl/participatie/handreikingparticipatie-duurzame-energie/participatie-in-beleidsfase> [Última consulta: 20/05/2020].

96 Projectparticipatie. Fuente: <https://www.klimaatakkoord.nl/participatie/handreikingparticipatie-duurzame-energie/projectparticipatie> [Última consulta: 20/05/2020].
} 
En el Klimaatakkoord se propone de impulsar la responsabilidad conjunta en la transición energética local a través de diferentes formas de participación de los vecinos en los proyectos a desarrollar ${ }^{97}$. Se trata de un objetivo ambicioso, debido a la dificultad que conlleva equilibrar las legítimas pretensiones de ganancias privadas de los inversores y emprendedores privados con las reivindicaciones de los vecinos de la comunidad y, con ello, dar una vertiente social a las acciones (por ejemplo, ser copropietarios y participar en las ganancias). Por este motivo se están promocionando decididamente las comunidades energéticas locales. Un proyecto actualmente en fase de realización se encuentra, por ejemplo, en la localidad de Moerdijk, y es promovido por la organización sin ánimo de lucro Energiek Moerdijk. En la citada zona se ha acordado entre el municipio, los vecinos, los inversores y los emprendedores, que el $25 \%$ de la propiedad de las 28 turbinas eólicas que se construirán se pondrá a disposición de la comunidad. Se convertirán en los llamados Dorpsmolens, molinos de pueblo, de propiedad local, cuya energía generada se distribuirá entre a los residentes del mismo municipio ${ }^{98}$.

\section{Acuerdos como base para la legislación posterior}

Como se ha podido apreciar en el apartado relativo a la Klimaatwet, la Ley del Clima es simplemente un marco legal que establece objetivos cuantitativos para el Gobierno. En cambio, el Klimaatakkoord establece la guía de directrices, concebida en clave colaborativa. La Klimaatwet y el Klimaatakkoord deben ser, por ende, el punto de partida para el desarrollo de la legislación posterior, tal como ya se ha apuntado. Por un lado, los Acuerdos se perfeccionan a través de las leyes, pasando del plano político al plano jurídico; por el otro, las leyes son fruto de acuerdos previos, por lo cual se aprecia su vertiente consensuada. Muchas leyes o decretos se han modificado y otros se han aprobado a raíz del

\footnotetext{
${ }^{97}$ Acerca de este tema, vid. Martha Roggenkamp, "The position of citizens in energy production in the Netherlands : is a new approach emerging?", Sharing the costs and benefits of energy and resource activity: legal change and impact on communities, ed. Lila Barrera-Hernández et al. (Oxford University Press, 2016), pp. 194-206.

98 Sobre este tema, véase la página web del Klimaatakkoord "Van windturbine naar dorpsmolen" $<$ https://www.klimaatakkoord.nl/themas/draagvlak-en-participatie/nieuws/2018/06/28/vanwindturbine-naar-dorpsmolen>. Se pueden consultar también las páginas web del proyecto: $<$ https://energiea16.nl/> y <https://energiekmoerdijk.nl/wind>. [Última consulta: 27/10/2019].
} 
Energieakkoord99; lo mismo que sucederá, sin duda, tras el Klimaatakkoord100, con el objetivo de trazar un camino, a través de una herramienta jurídicamente vinculante, para intentar conseguir los objetivos establecidos en los acuerdos.

Este enfoque resulta ciertamente positivo, aunque hay que destacar dos puntos que pueden ser objeto de crítica. En primer lugar, sería necesario potenciar la vertiente jurídica ya en la fase de determinación política de los acuerdos y en concreto contar en mayor medida con juristas en las mesas de negociación. En segundo lugar, en el caso del Energieakkoord, los firmantes declararon explícitamente que el Acuerdo no reemplazaría las leyes y regulaciones existentes ${ }^{101}$. El problema residiría, empero, en la legislación posterior al Acuerdo. El Consejo de Estado, en su Informe de 2018 ${ }^{102}$, advierte del peligro de que la ley pueda ser usada "instrumentalmente" para traducir o legitimar los acuerdos políticos y sociales. Sin embargo, el mismo Consejo de Estado advierte de la necesidad de que los acuerdos se recojan en normas con rango de ley, para que lo pactado se convierta en medidas jurídicamente vinculantes ${ }^{103}$. No cabe olvidar que la Klimaatwet establece obligaciones sólo para el Gobierno, por lo cual, sería necesario establecer obligaciones legales también para las demás administraciones, para las empresas y para los agentes sociales. Es preciso, por ende, que el siguiente paso sea la aprobación de un paquete legislativo coherente, como medio necesario para forjar legalmente todas las medidas pactadas en el Acuerdo y así vincular el resto de las partes firmantes.

\footnotetext{
99 Además del ya citado Decreto de Actividades de Gestión Medioambiental, por ejemplo, destacamos la Ley de energía eólica marina (Wet windenergie op zee).

100 Documento parlamentario $32813 \mathrm{~N}$. 348, consultable en <https://zoek.officielebekendmakingen.nl/kst-32813-348.html> [Última consulta: 20/05/2020]. El calendario legislativo para el Acuerdo Climático presentado por el Ministro de Asuntos Económicos y Clima se puede consultar en Documento parlamentario 32813 N. 394, de 23 de septiembre de 2019: https://zoek.officielebekendmakingen.nl/kst-32813-394.html [Última consulta: 20/05/2020].

101 Mulder, "Kolencentrales in de polder: private en publieke belangen in het Energieakkoord", RegelMaat, 34.2 (2019), 112-25.

102 Raad Van State, Jaarverslag van de Raad van State 2018, 2019 $<$ https://jaarverslag.raadvanstate.nl/2018/wp-

content/uploads/sites/6/2019/03/WEBVERSIE_Jaarverslag_2018.pdf>. [Última consulta: 12/12/2019].

${ }^{103}$ Raad Van State, Klimaatbeleid in wetgeving en akkoorden, cit.
} 


\section{Fortalecimiento del rol del gobierno respecto al parlamento}

Intrínsecamente conectado con lo que se acaba de exponer, resulta la erosión del rol del Parlamento o, lo que es lo mismo, el fortalecimiento de la posición del Gobierno en relación con la Asamblea parlamentaria. Así, mientras el Gobierno participa en las negociaciones, el Parlamento aparece como el mero redactor y conversor de acuerdos políticos en leyes. El Consejo de Estado remarca que "el legislador no puede simplemente «traducir» lo que otros han acordado [...y que] un debate social y político vivo sobre el contenido de la legislación es esencial para el buen funcionamiento de un Estado constitucional democrático. Ello requiere también una evaluación independiente por parte del legislador de los acuerdos políticos, sociales o administrativos. Si no se le da importancia o se le da menos importancia a este papel, se puede llegar a aprobar una ley que se base en la falta de apoyo político y social y, por lo tanto, no convenza a nadie. Entonces el legislador pierde el control y la autoridad" en el proceso legislativo ${ }^{104}$. En este sentido, KOOLE advierte como este tipo de acuerdos podrían poner en peligro la legitimidad democrática de las decisiones políticas ${ }^{105}$.

A tal propósito, el Consejo de Estado exhorta a que las decisiones más importantes sean tomadas "a dos manos", por el Gobierno y el Parlamento conjuntamente. Por este motivo, siempre de acuerdo con el Consejo de Estado, el Gobierno y el Parlamento deben seguir siendo conscientes de que la legislación va más allá de la suma de un compromiso entre intereses parciales o intereses particulares, así como más allá de un reparto justo de cargas y beneficios $^{106}$.

\section{Negociación con los grupos de interés}

Es preciso considerar, en primer lugar, que, en un marco político fragmentado, no es fácil encontrar el apoyo político estable para una legislación clara, incisiva y duradera: el Gobierno tiene menor acceso que en el pasado a apoyos y socios permanentes de coalición. Por este motivo, y para intentar prescindir de relaciones que cambian con frecuencia, se considera conveniente por parte de

\footnotetext{
104 Traducción propia. Jaarverslag van de Raad van State 2018, cit., p. 12. Acerca del tema véase también Koole, cit., p. 109.

${ }^{105}$ Koole, cit., p. 96.

106 Jaarverslag van de Raad van State 2018, cit., p. 17.
} 
los gobiernos, abrir caminos hacia acuerdos políticos y sociales ${ }^{107}$ que están dotados de mayor amplitud y, por tanto, de mayor consenso y estabilidad.

Por otro lado, en el caso de los Acuerdos climático y energético, se puede considerar establecer una importante ampliación: la transición energética y las medidas para hacer frente al cambio climático implican grandes inversiones por parte de ciudadanos y empresas; esfuerzos que estarían más dispuestos a efectuar si se hubieran comprometido en ellos, mediante la participación en su adopción. De la misma forma, estarían más dispuestos a satisfacerlas si existiera la certeza a largo plazo sobre las políticas que quiere implementar el Gobierno y si existiera el compromiso de que se trataría de políticas no sujetas a contundentes cambios de rumbo a corto plazo. Desde esta perspectiva, los acuerdos podrían ser muy ventajosos. Sin embargo, hay que considerar que, tras el Acuerdo, para dar certeza a los inversores resulta necesario un desarrollo normativo satisfactorio de las políticas pactadas. Este anclaje legal de un objetivo a largo plazo envía una señal importante de compromiso político que contribuye a la previsibilidad por parte de las empresas e inversores ${ }^{108}$.

En segundo lugar, se debe poner de relieve que, en el caso de los acuerdos analizados, la participación de los interesados en la fase de definición de las políticas y las medidas involucra principalmente a los actores, concretando sus roles, con el resultado que tales actores se comprometen y asumen responsabilidades más definidas y significativas en la implementación de las mismas. Por este motivo, en nuestra opinión, la participación de los diferentes actores en la fase de diseño de las políticas climáticas puede tener efectos considerablemente positivos sobre la fase de ejecución, para fortalecer la implicación tanto en los planes, como en las acciones concretas. De este modo, los diferentes sujetos intervinientes en los acuerdos se responsabilizan de su propia implementación. Es más, como apunta el Report del KWINK Groep acerca del Energieakkoord, éstos "pueden responsabilizarse mutuamente por las

107 En el mismo sentido, véase Paul de Beer, "The erosion of the Dutch Polder Model", en seminario Labour Relations in the Future World of Work, Paris, 11 de diciembre de 2017, p. 2. De acuerdo con el autor, "Exactly because socio-economic policy reforms are often fiercely contested, governments usually seek a compromise with the social partners in order to secure sufficient public and political support".

108 Albert Faber, Peter de Goede, Margot Weijnen, "Klimaatbeleid voor de lange termijn: van vrijblijvend naar verankerd", WRR-Policy Brief 5, 2016, p. 16. 
responsabilidades de todos"109. Esto es posible ya que "[l]a confianza y el entendimiento mutuo entre las partes participantes parece haber crecido a través de reuniones y discusiones frecuentes en el marco del Acuerdo de Energía. Las partes saben cómo llegar a compromisos y están dispuestas a entablar conversaciones entre ellas" y a buscar soluciones en situaciones de tensión ${ }^{110}$.

Frente a estas notas positivas, cabe tener presente que los acuerdos acentúan el carácter ya de por sí muy "neocorporativo" del proceso de formulación de las políticas sociales, económicas y ambientales neerlandesas. De tal manera, que la cultura de colaboración que hemos señalado podría encubrir un intento por parte de los grupos de interés de presionar sobre los gobiernos en una doble dirección. Por un lado, en la misma área del Acuerdo, de manera que, como afirma KOOLE ${ }^{111}$, una vez firmado el Acuerdo, no podrá modificarse casi ningún aspecto por parte del Gobierno en las políticas y en la legislación posteriores, dada la amenaza de la pérdida de apoyo de los que los firmaran. Por esta razón, los acuerdos ejercerían excesiva presión sobre el Gobierno, ya que se tomarían muy pocas decisiones independientes respecto a los acuerdos y, por ende, se ejercitarían presiones, así mismo, sobre la determinación gubernamental y legislativa de las medidas de interés público. En segundo lugar, los acuerdos, según el Consejo de Estado ${ }^{12}$, podrían ofrecer a las partes la oportunidad de avanzar con nuevas pretensiones en otras áreas y amenazar con cancelar los acuerdos anteriores. Se entraría así en un círculo vicioso basado en acuerdos que influyen en otros acuerdos, que podría acentuarse aún más en el futuro.

Para KOOLE, el papel cada vez más relevante que las organizaciones en general - no solamente los grupos de interés - desempeñan en la política neerlandesa debilitaría la "política legitimada", decidida por el Gobierno. Así pues, la "política legitimada" estaría así obligada no solamente a tener en cuenta estas organizaciones, sino también a llegar a compromisos con ellas. Coincidiendo con las consideraciones de KOOLE, podría tratarse de un peligroso juego de equilibrios, en el que las partes dependen las unas de las otras: un juego que aumenta la interdependencia y la dependencia. Este juego se complica al crecer

\footnotetext{
109 KWINK Groep, Evaluatie Energieakkoord..., cit., p. 14.

110 Ibidem.

111 Koole, cit., p. 95.

112 Jaarverslag van de Raad van State over 2013, cit., p. 13.
} 
el número de los actores, como resulta en los dos acuerdos. Además, al aumentar el número de las organizaciones, sería más difícil llegar a un punto de equilibrio y los costes de transacción para llegar al acuerdo aumentarían también ${ }^{113}$.

Una consecuencia del modelo descrito es que la toma de decisiones y el ejercicio del poder gubernamental se organizan menos como una pirámide jerárquica de poderes y de responsabilidades y más como un entramado en forma de red horizontal. En este marco, por un lado, los gobiernos (a todos los niveles) involucrados son menos capaces de actuar discrecionalmente, como consideren conveniente; pero, por otro, a través de políticas y decisiones consensuadas pueden representar mejor los intereses que justifican el ejercicio del propio poder. En resumen: los gobiernos son cada vez más actores de un sistema en red que necesita de equilibrios, en lugar de ser autónomos y de mover los hilos de estructuras jerárquicas.

A lo anteriormente dicho, debe añadirse la consideración de que los intereses en la mesa de negociaciones no siempre tienen el mismo peso, así que, sin mecanismos de control en las negociaciones, los equilibrios podrían verse comprometidos. MULDER ${ }^{114}$ subraya este aspecto como uno de los problemas más importantes del Energieakkoord, con el riesgo de repetirse y/o ampliarse en el Klimaatakkoord. En cuanto a éste último, según MULDER, algunos de los puntos del Acuerdo propuestos parecen favorecer a las partes participantes en las mesas, sobre todo a determinadas empresas, mientras que los costes se transfieren principalmente a las partes que no están sentadas a la mesa - en la mayoría de los casos, a los ciudadanos - Así mismo, opina que "[c]on una organización central, donde las partes se consultan entre sí para tomar las mejores decisiones para la sociedad en su conjunto, no se puede esperar que estas partes pierdan de vista sus propios intereses. La consecuencia de esto es que un enfoque central conlleva el riesgo de que, bajo la apariencia de interés social, se adopten medidas que sirvan principalmente a ciertos intereses individuales"115. Por este motivo, resulta imprescindible, por un lado, que se

\footnotetext{
113 Koole, cit., p. 102.

${ }^{114}$ Mulder, "Kolencentrales in de polder: private en publieke belangen in het Energieakkoord",cit. 115 Machiel Mulder, "Klimaatberaad koerst af op ondoelmatig beleid", Jaargang, 103.december (2018), pp. 568-73.
} 
garanticen los procedimientos democráticos en la fase de negociación de los acuerdos y, por el otro, sobre todo, que se protejan, por parte del Gobierno, los derechos y los intereses de los sujetos no participantes en las mesas de negociación.

En una sociedad democrática, es tarea del gobierno velar por el interés general, que a menudo colisiona con las expectativas de los grupos de interés, partes de los acuerdos y sus intereses particulares. Por este motivo, según GLASBERGEN ${ }^{116}$ las responsabilidades políticas nunca pueden compartirse totalmente con los grupos de interés ${ }^{117}$.

El elenco de las partes firmantes del Klimaatakkoord ${ }^{18}$ cuenta con ausencias de gran calado: se trata de algunas organizaciones ambientales, que participaron en las mesas de negociación del Acuerdo, como, por ejemplo, Milieudefensie y Greenpeace ${ }^{119}$. Cuando se presentó el borrador del Acuerdo Climático, el 21 de diciembre de 2018, las citadas organizaciones se mostraron muy decepcionadas por la falta de ambición de las medidas propuestas y por la presencia de medidas que eran muy favorables a algunos sectores y a ciertas organizaciones económicas ${ }^{120}$. Asimismo, el 9 de mayo de 2019 las organizaciones ambientales remitieron una carta al Ministro de Economía para expresar sus preocupaciones acerca del Acuerdo ${ }^{121}$ y su insatisfacción acerca de las medidas renegociadas entre las partes $y$, finalmente, no aceptaron subscribir el Acuerdo.

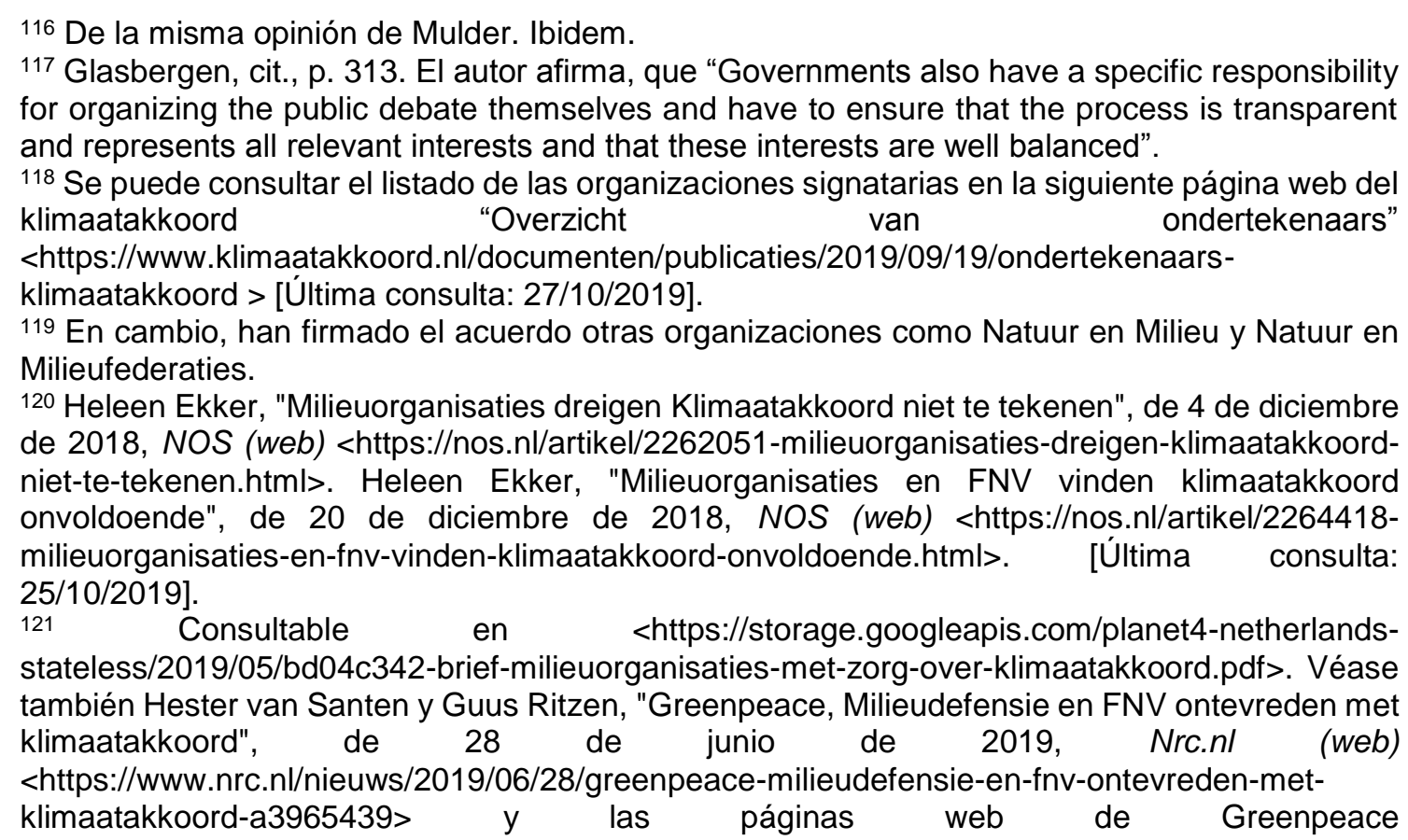


En 1998, WEGGEMAN apuntaba a la dificultad de utilizar el modelo polder en materia medioambiental ${ }^{122}$; puesto que, para que los asuntos medioambientales se pudieran tratar a través del modelo polder, sería necesario tener en cuenta las naturalezas incompatibles de los intereses ecológicos y de los intereses económicos $\mathrm{y}$, a este tenor, la posibilidad de que la toma de decisiones participativa, a través del diálogo entre el mayor número posible de partes interesadas, no siempre resulte fructífera. En este sentido, destaca WEGGEMAN: "un modelo de polder verde no debe tener la ambición de unir valores opuestos, sino 'solamente' de mitigar las contradicciones" y para ello es necesario el reconocimiento institucional del conflicto entre los valores e intereses económicos y ecológicos; sin el reconocimiento institucional de tal conflicto "no es posible aplicar las reglas históricamente desarrolladas del polder (verde) de una manera clara"123. Veinte años más tarde, el Acuerdo sobre el Clima ha revelado, posiblemente, las dificultades, aunque no la imposibilidad, para poder alcanzar el necesario encaje entre valores e intereses diversos con cierta precisión.

\section{CONCLUSIONES}

Tras el análisis y la valoración de los dos Akkoords se pueden formular algunas conclusiones acerca de su consideración como instrumentos base de coordinación para las políticas neerlandesas de cambio climático. Ante todo, cabe señalar que estos Acuerdos se insertan en la tradición política e institucional neerlandesa $\mathrm{y}$, probablemente, su traslado a otro sistema institucional no garantizaría el mismo resultado o, posiblemente, conllevaría una serie de dificultades añadidas para su negociación e implementación, más allá de las propias del sistema de origen.

Asumida esta premisa, y teniendo en cuenta los elementos críticos apuntados, estimamos que los Acuerdos analizados representan interesantes instrumentos

\footnotetext{
<https://www.greenpeace.org/nl/klimaatverandering/18028/grote-zorgen-over-voortgangklimaatakkoord/>; $\quad<$ https://www.greenpeace.org/nl/klimaatverandering/19145/waaromgreenpeace-het-klimaatakkoord-niet-voldoende-vindt/> [Última consulta 25/10/2019].

122 J. Weggeman, "De ambitie van een groen poldermodel", Reformatorisch Dagblad, 11/11/1998 $<$ https://www.digibron.nl/search/detail/012de04ab09e6a8af1ea409a/de-ambitie-van-een-groenpoldermodel> [Ulltima consulta 25/10/2019] (traducción propria).

123 Ibidem.
} 
que sirven como base para la coordinación de políticas de cambio climático. Así pues, con este propósito, destacamos los siguientes aspectos:

a) En cuanto a los factores organizativos y estructurales, recalcamos los complejos mecanismos de trabajo instituidos para la preparación y la negociación de los acuerdos y, en una fase posterior, la elaborada organización para la implementación y supervisión de los mismos. Asimismo, cabe señalar la minuciosa información pública que los acompaña.

b) A través de los mecanismos previstos en los Acuerdos, se involucran el conjunto de instituciones y de agentes sociales en el establecimiento y ejecución de políticas medioambientales a diferentes escalas y en los diferentes sectores. De tal suerte que se procura dar vida a un puzle de actores que se comprometen a llevar a cabo actualizaciones coordinadas y subsidiarias, para la consecución de un fin común. Asimismo, la participación social en los proyectos, la búsqueda de consenso y de aceptación por parte de la población de las políticas y de las medidas concretas devienen el pilar fundamental para el éxito de las políticas de cambio climático, sobre todo en una sociedad democrática que depende cada vez más del consentimiento de los gobernados.

c) Respecto al marco conceptual, estimamos muy interesante el enfoque de un acuerdo político, para compartir con los diferentes niveles institucionales y actores sociales desafíos y hojas de ruta en la transición energética y la lucha contra el cambio climático. Aun así, cabe volver a recordar que se trata de instrumentos de carácter político. Por este motivo, consideramos que deben representar tan solo un punto de inicio y un marco, si bien consistente, para el desarrollo de la necesaria legislación posterior. En efecto, por una parte, se precisa un desglose en instrumentos concretos de coordinación entre Administraciones públicas; por otra, se requiere el necesario desarrollo legislativo de los acuerdos, para que resulten jurídicamente vinculantes, de manera que todos los actores involucrados ${ }^{124}$ en estos acuerdos se transformen en destinatarios de las normas, teniendo así que asumir corresponsabilidad en el logro de los objetivos establecidos.

\section{BIBLIOGRAFÍA Y WEBGRAFÍA BÁSICA}

${ }^{124}$ Raad Van State, Klimaatbeleid in wetgeving en akkoorden, cit., p. 27. 
van 't Lam, Valérie, van der Maden, E. C. «De informatieplicht en de verplichting tot het treffen van energiebesparende maatregelen uit het Activiteitenbesluit onder de loep», Bedrijfsjuridische berichten, 37.Junio 2018 (2018), 135-37.

van 't Lam, Valérie, «Aangenomen Klimaatwet: een belangrijke symboolfunctie geformaliseerd", Stibbe $<$ https://www.stibbe.com/en/news/2019/june/aangenomen-klimaatwet-eenbelangrijke-symboolfunctie-geformaliseerd>.

Akerboom, Sanne, «Between Public Participation and Energy Transition: the case of wind farms», 2018 (tesis doctoral).

Barnhoorn, Lianne, «Participatie verankerd in nieuwe Klimaatwet», Pels Rijcken $<$ https://blogklimaatenergie.nl/2019/06/04/participatie-verankerd-in-nieuweklimaatwet/>.

de Beer, Paul, «The erosion of the Dutch Polder Model», en Labour Relations in the Future World of Work, Paris, 2017.

Berger, Gerald, Pohoryles, Ronald J. «Policy Integration and Capacity-Building in Regional Sustainable Development: Analysis of Experiences in Europe», en 2004 Berlin Conference on the Human Dimension of Global Environmental Change, 2006, pp. 1-22.

Catenacci, Michela, «Environmental policy integration at Regional and Local Levels: setting the problem into context», en Governance for the Environment: A Comparative Analysis of Environmental Policy Integration, ed. Alessandra Goria, Alessandra Sgobbi, y Ingmar von Homeyer (Edward Elgar Publishing, 2010), pp. 43-76.

Ekker, Heleen, «Milieuorganisaties dreigen Klimaatakkoord niet te tekenen», NOS (web) <https://nos.nl/artikel/2262051-milieuorganisaties-dreigenklimaatakkoord-niet-te-tekenen.html>.

—_, «Milieuorganisaties en FNV vinden klimaatakkoord onvoldoende», NOS (web) <https://nos.nl/artikel/2264418-milieuorganisaties-en-fnv-vindenklimaatakkoord-onvoldoende.html>.

Faber, Albert, Peter de Goede, y Margot Weijnen, Klimaatbeleid voor de lange termijn: van vrijblijvend naar verankerd, WRR-Policy Brief 5, 2016.

van Gastel, Edwin, "Klimaatberaad: 'Klimaatakkoord moet dubbel verankerd worden'», SolarMagazine <https://solarmagazine.nl/nieuws-zonneenergie/i18640/klimaatberaad-klimaatakkoord-moet-dubbel-verankerd-worden>.

Glasbergen, Pieter, «The green polder model: Institutionalizing multi-stakeholder processes in strategic environmental decision-making», European Environment, 12.6 (2002), 303-15 .

van der Goot, Edo, «Eerste Kamer stemt in met Klimaatwet: Dit zijn de belangrijkste punten", Nu.nl (web) <https://www.nu.nl/politiek/5912553/eerstekamer-stemt-in-met-klimaatwet-dit-zijn-de-belangrijkste-punten.html>. 
Graaf, K. J., Jans, J. H. «The Urgenda Decision: Netherlands Liable for Role in Causing Dangerous Global Climate Change», Journal of Environmental Law, 27.3 (2015), 517-27.

Hoppe, Thomas; Arentsen, Maarten; Mikkilä, Mirja; Linnanen, Lassi, Transition management and the sustainable nutrients economy in the Netherlands, Tutkimusraportti Research Report 25, 2012, pp. 1-37.

Koole, Ruud A., «ls een 'akkoorden-democratie' wel een democratie?», RegelMaat, 34.2 (2019), 95-111.

Koster, Harold, «Het ontwerp klimaatakkoord», Bedrijfsjuridische berichten, 3, 2019.

KWINK Groep, Evaluatie Energieakkoord voor duurzame groei. Onderzoek naar de werking van de aanpak van het Energieakkoord voor duurzame groei. (The Hague, 2016).

Lambregtse, Corien, «Overleg tussen politiek en polder: Reconstructie Klimaatakkoord», SER <https://www.ser.nl/nl/Publicaties/reconstructieklimaatakkoord>.

Mulder, Machiel, «Klimaatberaad koerst af op ondoelmatig beleid», Jaargang, 103.december (2018), 568-73.

- "Kolencentrales in de polder: private en publieke belangen in het Energieakkoord», RegelMaat, 34.2 (2019), 112-25.

Musch, Elisabeth, «The Energy Agreement (Energieakkoord) of the Netherlands in the European context», en ECPR General Conference, 2018, pp. 1-22.

Nederhof, Koen, Edwin Timmer, «Provincies zien enthousiasme voor klimaatminaret afnemen», De Telegraaf (web) $<$ https://www.telegraaf.nl/nieuws/858941704/provincies-zien-enthousiasmevoor-klimaatminaret-afnemen>.

Nowlin, Matthew C., Environmental Policymaking in an Era of Climate Change (Routledge, 2019).

Parejo Navajas, Teresa, «La victoria de Urgenda: el inicio de la lucha judicial frente al cambio climático", Revista española de derecho administrativo, 177 (2016), 259-79.

Perlaviciute, Goda; Squintani, Lorenzo; Metz, Gido, De mening van inwoners van Vinkhuizen-Noord over een aardgasvrij Vinkhuizen-Noord, 2019.

PBL, "Kortetermijnraming voor emissies en energie in 2020", de 25 de enero de $2019<\mathrm{Lttps}$ ://www.pbl.nl/publicaties/kortetermijnraming-voor-emissies-enenergie-in-2020>.

- "Het Klimaatakkoord: effecten en aandachtspunten", $<$ https://www.pbl.nl/publicaties/het-klimaatakkoord-effecten-enaandachtspunten>. 
- "Gemeentelijke bestuurskracht en de energietransitie", de 6 de septiembre de 2019, <https://www.pbl.nl/publicaties/gemeentelijkebestuurskracht-en-de-energietransitie>.

Raad Van State, Jaarverslag van de Raad van State over 2013, 2014, $<$ https://jaarverslag.raadvanstate.nl/2013/downloads/jaarverslag-raadvanstate2013.pdf>.

—, Klimaatbeleid in wetgeving en akkoorden. Verslag van de Expertbijeenkomst van de Raad van State op 20 maart 2018, 2018, pp. 22-25.

- Jaarverslag van de Raad van State 2018, 2019 $<$ https://jaarverslag.raadvanstate.nl/2018/wpcontent/uploads/sites/6/2019/03/WEBVERSIE_Jaarverslag_2018.pdf>.

Rodríguez García, Noel, «Responsabilidad del Estado y cambio climático: el caso Urgenda c. Países Bajos», Revista Catalana de Dret Ambiental, 7.2 (2016).

Roggenkamp, Martha M., «The position of citizens in energy production in the Netherlands : is a new approach emerging?», en Sharing the costs and benefits of energy and resource activity: legal change and impact on communities, ed. Lila Barrera-Hernández, Barry Barton, Lee Godden, Alastair Lucas, y Rønne Anita (Oxford University Press, 2016), pp. 194-206.

van Santen, Hester, Guus Ritzen, «Greenpeace, Milieudefensie en FNV ontevreden met klimaatakkoord", Nrc.nl (web) <https://www.nrc.nl/nieuws/2019/06/28/greenpeace-milieudefensie-en-fnvontevreden-met-klimaatakkoord-a3965439>.

Schaap, Linze, Decentrale autonomie?, 2012 $<$ https://www.vng.nl/files/vng/20121024_pre_monitoring_report_schaap.pdf>

van Schie, Matthijs, «Provincies in hun maag met windmolens: verzet groeit», EISevier Weekblad

(web) $<$ https://www.elsevierweekblad.nl/nederland/achtergrond/2019/08/draagvlakvoor-windmolens-neemt-steeds-verder-af-705147/>.

Schreuder, Yda, «The Polder Model in Dutch Economic and Environmental Planning», Bulletin of Science, Technology \& Society, 21.4 (2001), 237-45.

Smith, Adrian, Florian Kern, «The transitions storyline in Dutch environmental policy», Environmental Politics, 18.1 (2011), 78-98.

Torres Pereira, Artur, Jean-Pierre Liouville, Report on Local and regional democracy in the Netherlands - CG(26)7FINAL, 2014 $<$ https://search.coe.int/congress/pages/result_details.aspx?objectid=090000168 071a7f4\#_ftnref11>.

Touwen, Jeroen, Coordination in Transition: The Netherlands and the World Economy, 1950-2010 (Brill, 2014). 
Verdaas, Johannes Cornelis, «Energie \& gebiedsontwikkeling: een winnende combinatie» <http://files.m11.mailplus.nl/user31100268/16112/EssayCo_Verdaas.pdf>.

Verschuuren, Jonathan, «The State of the Netherlands v Urgenda Foundation: The Hague Court of Appeal upholds judgment requiring the Netherlands to further reduce its greenhouse gas emissions", Review of European, Comparative and International Environmental Law (RECIEL), 28 (2019), 94-98.

Vos, Kees, Paul de Beer, Lieve De Lathouwer, «Verleden en toekomst van het poldermodel», Tijdschrift voor Arbeidsvraagstukken, 18.4 (2002), 403-10.

Weggeman, J., «De ambitie van een groen poldermodel», Reformatorisch Dagblad, 1998.

Van der Woude, Wytze, «De Grondwet - Artikel 124 - Autonomie en Medebewind", Wetenschappelijk Comentaar op de Nederlandse Grondwet $<$ https://www.nederlandrechtsstaat.nl/module/nlrs/script/viewer.asp?soort=com mentaar\&artikel=124>.

Woudstra, Roel; Sible Schöne, Kirsten Notten, Albert Koers, Rob Rietveld, Klimaatakkoord 2018. Maatschappelijke acceptatie en participatie, 2018 $<$ https://www.klimaatakkoord.nl/themas/draagvlak-en-

participatie/documenten/rapporten/2018/07/02/eindrapport-raadplegenburgernetwerken>.

van Zundert, J.W., «Duurzame energie en omgevingsrecht», $<$ https://www.navigator.nl/thema/1130/duurzame-energie-en-omgevingsrecht>.

\section{Agradecimientos}

El presente estudio es fruto de la estancia de investigación realizada en la Facultad de Derecho de la Rijksuniversiteit Groningen (Países Bajos), en concreto en el Department of Business Law, European Law and Tax Law bajo la supervisión del Profesor Dr. Lorenzo Squintani, a quien me gustaría expresar mi más sentido agradecimiento por la atención y por los consejos e indicaciones que me ha brindado. Asimismo, quisiera hacer extensiva mi gratitud al Profesor Dr. Stefan Weishaar y a todos los profesores e investigadores de la misma Universidad con los que he podido compartir inquietudes y opiniones acerca del objeto de este artículo y acerca de mi investigación doctoral. En cualquier caso, las opiniones expresadas, así como los eventuales errores contenidos en el presente trabajo, son de exclusiva responsabilidad de quien escribe. 